\title{
PENSIONES DE ALIMENTOS. ALGUNAS RAZONES PARA EXPLICAR EL FENÓMENO DEL INCUMPLIMIENTO
}

\author{
CHILD SUPPORT. SOME REASONS TO EXPLAIN THE \\ PHENOMENON OF ALIMONY NON-PAYMENT
}

MACARENA VARGAS PAVEZ*

PAZ PÉREZ AHUMADA**

\section{RESUMEN}

El trabajo analiza el incumplimiento del pago de las pensiones de alimentos en Chile, en particular las razones que pueden explicar la profunda crisis por la cual atraviesa el sistema de ejecución de familia. Hasta ahora el fenómeno ha sido examinado únicamente desde la perspectiva del comportamiento del deudor sin considerar otras dimensiones que permitirían avanzar hacia soluciones más efectivas. El trabajo plantea algunas propuestas en este sentido, tales como el diseño de un procedimiento de ejecución de familia, la articulación del enfoque de gestión administrativa con el de derechos fundamentales y el levantamiento periódico de información, entre otras.

\footnotetext{
*Abogada de la Universidad Diego Portales. Magíster en Gestión y Políticas Públicas por la Universidad de Chile. Doctora en Derecho, Pontificia Universidad Católica de Valparaíso (PUCV). Directora del Departamento de Derecho Procesal y miembro del Programa de Reformas Procesales y Litigación, Universidad Diego Portales, Santiago, Chile. ORCID: https://orcid.org/0000-0003-4130-5276. Correo: macarena.vargas@udp.cl.
}

**Abogada Universidad de Valparaíso. Magister en Derecho Internacional de los Derechos Humanos por Universidad Diego Portales. Máster en Derecho y Genero, Universidad de Jaén, España. Jueza titular del Tercer Juzgado de Familia de Santiago, Santiago, Chile. ORCID: https://orcid.org/0000-0001-7670-0829. Correo: paz_perez_a@hotmail.com.

Trabajo recibido para evaluación el 1 de junio de 2021 y aceptado para su publicación el 15 de diciembre de 2021. 
Palabras clave: Pensiones de alimentos, Deuda de pensión de alimentos, Medidas de apremio, Procedimiento de ejecución, Derecho procesal, Derecho de familia.

\section{ABSTRACT}

This paper analyzes the non-payment of alimony in Chile, in particular the reasons that may explain the deep crisis of the family enforcement system. Until now, this phenomenon has been examined only from the perspective of the debtor's behavior without considering other dimensions that would allow us to move towards more effective solutions. This paper raises some proposals in this regard, such us the design of a family enforcement procedure, how to articulate the court management approach with that of fundamental rights and the periodic gathering of information, among others.

Keywords: Alimony, Alimony debt, Measures of constraint, Enforcement proceedings, Procedural law, Family law.

\section{INTRODUCCIÓN}

La retención del $10 \%$ de los fondos de pensiones de las AFP ha develado un problema de antigua data, pero de escasa atención del mundo jurídico. Por varias semanas, el incumplimiento en el pago de las pensiones de alimentos acaparó los titulares de los medios de prensa y la atención de las autoridades un poco pasmadas ante la magnitud y repercusiones de este fenómeno.

Los datos que conocemos son elocuentes. El 84\% de las pensiones alimenticias decretadas por los tribunales de familia son incumplidas; ${ }^{1}$ en 9 de cada 10 casos las demandantes son mujeres ${ }^{2}$ y un $65 \%$ del total de

\footnotetext{
${ }^{1}$ Boletín $\mathrm{N}^{\circ} 13.330-07$. Proyecto de ley, de S. E. el Presidente de la República, que incorpora a los deudores de pensiones de alimentos al Boletín de Informaciones Comerciales. Allí se señala: "La realidad de nuestro país muestra que el $84 \%$ de los demandados en causas de alimentos no paga la pensión de alimentos fijada por el Tribunal, suma de dinero que resulta crucial para efectos de la subsistencia de los alimentarios. Esta deuda, según datos del Poder Judicial, asciende a un total de 180.000 millones de pesos".

${ }^{2}$ Cortez-Monroy, Fabiola, Opinión: "Pago de pensiones de alimentos: ¿de quién es la deuda?”,
} 
personas que no reciben la pensión de alimentos corresponde a la población de menos ingresos de nuestro país. ${ }^{3} \mathrm{Si}$ bien existe discusión en torno al origen de la cifra del 84\% y la Dirección de Estudios de la Corte Suprema ha aportado nuevos datos sobre el particular, ${ }^{4}$ lo cierto es que nos encontramos frente a un grave problema de incumplimiento de las resoluciones judiciales.

Si bien la legislación sustantiva contempla un amplio catálogo medidas contra los deudores de alimentos la evidencia muestra que ellas parecen no ser efectivas. El camino que madres, hijos/as deben seguir para obtener el pago de lo debido es -en muchas ocasiones- largo e infructuoso. Ello ocurre porque se ha seguido utilizando, tanto desde el punto de vista legal como práctico, un procedimiento que replica el modo de operar del antiguo sistema de los tribunales de menores, sin una evaluación acerca de su coherencia con los derechos fundamentales y sin los adecuados ajustes que de ello se derivan.

Así, por ejemplo, el procedimiento obliga a los alimentarios/as a solicitar estos apremios cada vez que hay un nuevo incumplimiento, debiendo atravesar varias etapas antes de conseguir que se despache la medida solicitada. Ello tarda en promedio poco más de un mes. Y cuando la medida es finalmente obtenida, se produce la paradoja de que al alimentante le basta con depositar una pequeña suma de dinero para enervar el apremio, debiendo el alimentario/a iniciar nuevamente las gestiones judiciales, cuestión que en algunos casos puede repetirse mes a mes en una suerte de espiral infinito.

Pero este problema no es nuevo. Desde el año 2011 en adelante se han venido planteando diversos proyectos de ley que buscan revertir esta situación. ${ }^{5}$ Ello se ha hecho principalmente por la vía de endurecer las sanciones a los alimentantes, de modo de "persuadirlos" a cumplir con

2020, https://www.ciperchile.cl/2020/08/06/pago-de-pensiones-de-alimentos-de-quien-es-la-deuda/, consultada: 27 de abril de 2021.

${ }^{3}$ Cortez-Monroy, cit. (n. 2).

${ }^{4}$ Dirección de Estudios Corte Suprema, "Problemáticas de la etapa de cumplimiento en materia de alimentos. Una visión práctica", 2020, http://decs.pjud.cl/articulo-problematicas-de-la-etapa-decumplimiento-en-materia-de-alimentos-una-vision-practica, consultada: 9 de marzo de 2021.

${ }^{5}$ Desde 2011 en adelante se identifican trece proyectos de ley: 1) Boletín 7.765-07. 2); Boletín $\mathrm{N}^{\circ} 10.259-18$; 3) Boletín $\mathrm{N}^{\circ} 10.450-18$; 4) Boletín $\mathrm{N}^{\circ} 11.738-18$; 5) Boletín $\mathrm{N}^{\circ} 11.813-18$; 6) Boletín 12.068-18; 7) Boletín 12.147-18; 8) Boletín 12.182-18; 9) Boletín $\mathrm{N}^{\circ} 12.244-18$; 10) Boletín $\mathrm{N}^{\circ} 12.394$ 18; 11) Boletín $\mathrm{N}^{\circ} 13.330-07$; 12) Boletín 13.465-18 y Boletín 14.077-18. 
el pago de las pensiones adeudadas. Así, por ejemplo, en marzo del 2020 se presentó una propuesta que busca incorporar -dentro del Boletín de Informaciones Comerciales, comúnmente conocido como DICOM- a los deudores de pensiones alimenticias. ${ }^{6}$ Lo mismo ocurre con el proyecto de ley presentando en marzo del 2021, donde se propone la creación de un registro nacional de deudores de pensiones de alimentos, además, de otras medidas, que buscan establecer mejoras en la actual retención de impuestos o en los impedimentos para la obtención de la licencia de conducir y el pasaporte, entre otras. ${ }^{7}$

En general, estas propuestas abordan el problema de manera unidireccional, como si la única razón del no pago de las pensiones fuese la existencia de deudores contumaces respecto de los cuales no queda más remedio que elevar los costos del incumplimiento. Es cierto que en buena parte el no pago de las pensiones se debe a este tipo de comportamiento, pero una mejora sustantiva pasa también por tomar medidas que se hagan cargo de las otras razones que explican la ineficacia del actual sistema de ejecución en sede de familia.

El trabajo que a continuación se presenta tiene como objetivo analizar algunas de las razones que explican este fenómeno en nuestro país y su mantención en el tiempo. Antes de comenzar es necesario realizar dos precisiones metodológicas. En primer lugar, si bien este trabajo reflexiona sobre las razones que pueden estar detrás del incumplimiento, resulta imposible agotar todas las existentes en un estudio de estas características. Así, dejamos fuera del análisis elementos tan importantes como los aspectos sociológicos e históricos que sin duda están a base de este tópico. En segundo lugar, tampoco se estudian en profundidad las posibles soluciones para enfrentar este fenómeno ni menos aquellas contenidas en el derecho comparado. Hacia el final del trabajo se plantean algunas propuestas con el objetivo de hacerse cargo de las razones desarrolladas y -como decimos en las conclusiones- abrir el debate en esta materia.

Dicho lo anterior, el trabajo se ha estructurado sobre la base de cuatro

\footnotetext{
${ }^{6}$ Boletín 13.330-07, Proyecto de ley que incorpora a los deudores de pensiones de alimentos al Boletín de Informaciones Comerciales, 23 de marzo de 2020.

${ }^{7}$ Boletín 14.077-18, Proyecto de ley que Modifica la Ley No 14.908 , Sobre abandono de familia y pago de pensiones alimenticias, y crea el Registro Nacional de Deudores de Pensiones de Alimentos, 8 de marzo de 2021. Al cierre de la edición de este artículo, el proyecto se encontraba aprobado y publicado, como Ley $\mathrm{N}^{\circ} 21.389$.
} 
secciones. En una primera parte se analiza la ausencia de un enfoque de derechos humanos en la comprensión de la ejecución de las pensiones de alimentos y su impacto en la eficacia de las resoluciones judiciales en este ámbito. En la segunda sección se aborda el diseño legal de la ejecución de los alimentos tanto desde una perspectiva orgánica como procedimental, así como la lógica que está detrás de este diseño y su incidencia en la eficacia del cumplimiento.

En la tercera parte se examina cómo la falta de evidencia empírica impide demarcar, cuantitativa y cualitativamente, el fenómeno del incumplimiento de los alimentos y, por ende, avanzar hacia soluciones efectivas. Por último, en la cuarta sección se analiza la cultura legal y su efecto en las prácticas de jueces/as, funcionarios/as judiciales y abogados/as de familia. Finaliza el trabajo con algunas conclusiones y propuestas.

Para el desarrollo de este trabajo se ha empleado la metodología propia de las ciencias jurídicas, a través del análisis dogmático de textos y normas jurídicas con el objeto de comprender lo que el derecho vigente establece y sus posibles interpretaciones. Ello se complementa con un análisis crítico de las prácticas judiciales en esta materia, con el fin de entender las dinámicas operativas del sistema de justicia de familia, desde la perspectiva del rol que cabe a sus operadores/as. Lo anterior permite comprender -desde el inicioque este trabajo no se desarrolla exclusivamente desde una perspectiva dogmática, sino que integra aquella corriente que en derecho comparado se conoce como Law and Society, la cual mediante la utilización métodos provenientes de las ciencias sociales pretende enriquecer la comprensión del derecho, mediante el estudio de cómo este funciona en la práctica.

\section{PRIMERA RAZÓN: EL CUMPLIMIENTO DE LA PENSIÓN DE ALIMENTOS NO ES UN TEMA DE DERECHOS FUNDAMENTALES.}

Pese a que en las últimas décadas el derecho de familia ha experimentado transformaciones radicales,${ }^{8}$ aumentando su radio de acción y comple-

\footnotetext{
${ }^{8}$ Algunos ejemplos de ello son la Ley de Acuerdo de Unión Civil (Ley 20.830); Ley de identidad de género que regula el cambio de sexo y nombre registral (Ley 21.120) o la Ley de aborto en tres causales (Ley 21.030), donde hay participación de los jueces y juezas de familia en casos de abortos de niñas y adolescentes.
} 
jizando su contenido, aún persiste la idea de que los conflictos de familia son asuntos de baja complejidad técnica. ${ }^{9}$

Las pensiones de alimentos son un claro ejemplo de ello. Al ser consideradas desde una perspectiva tradicional -esto es, como un asunto sencillo y prácticamente de resolución mecánica- su abordaje no permite incorporar en su tratamiento discusiones claves sobre derechos fundamentales como el derecho del niño/a de tener un nivel de vida adecuado para su desarrollo holístico, el derecho a la igualdad y la no discriminación ${ }^{10}$ o el derecho a la tutela judicial efectiva, aspectos que tienen directa incidencia en la fijación del monto de los alimentos y más tarde en su cumplimiento forzado. ${ }^{11}$

Por otra parte, tradicionalmente, la ejecución ha sido considerada como una fase secundaria y marginal del proceso declarativo, al cual no se le aplicarían las exigencias del debido proceso. En general, los textos de estudio se limitan a una descripción normativa de las instituciones procesales sin ahondar en la directa vinculación de la ejecución con los derechos fundamentales y el desarrollo que este tópico ha experimentado a la luz del Derecho Internacional de los Derechos Humanos. ${ }^{12}$

Así la combinación entre un asunto infravalorado (pensión de alimentos) y un procedimiento semi abandonado (ejecución) puede explicar el escaso desarrollo e interés que el pago de las pensiones alimenticias

\footnotetext{
${ }^{9}$ Véase un interesante trabajo donde se presentan algunas lecturas para comprender los problemas de los tribunales de familia. Una de ellas es precisamente el factor reputacional de la justicia de familia. Fuentes, Claudio, "Los dilemas del juez de familia", Revista Chilena de Derecho, 2015, Vol. 42, no 3, pp. 957-961.

${ }^{10}$ Arancibia, María José; Cornejo, Pablo, "El Derecho de familia en Chile. Evolución y nuevos desafíos”, Ius et Praxis, 2014, Vol. 20, № 1, p. 287. Solo para ilustrar el contenido: “... a lo cual se suma la necesidad de eliminar los últimos vestigios todavía existentes de la antigua legislación fundada sobre una distribución de roles hoy considerada obsoleta, donde el marido aparecía no sólo como el proveedor, sino también como el nexo entre la familia y el ámbito público, mientras a la madre correspondía un dominio sobre el ámbito doméstico, reflejado particularmente en la maternidad y la crianza de los hijos, modelo cuya subsistencia resulta contraria a la igualdad reconocida en el artículo 19 $\mathrm{N}^{\circ} 2$ de la Constitución Política". Este orden de género y la disrupción que significa el empoderamiento de la mujer que cobra la pensión explica los problemas del incumplimiento desde lo cultural.

${ }^{11}$ Pérez, Paz, Incumplimiento de alimentos en la justicia de familia, DER Ediciones, Santiago, 2021, p. 57.

${ }^{12}$ Vargas, Macarena, El derecho a la ejecución forzada. Noción e implicancias a la luz de la jurisprudencia de la Corte Europea de Derechos Humanos, Ediciones Universitarias de Valparaíso, Valparaíso, 2019, pp. 29, y 38-42.
} 
concita en el medio jurídico nacional y que ninguno de los proyectos de ley presentados en el Congreso Nacional haya sido finalmente aprobado, descontando, desde luego, los recientemente despachados.

La ausencia de consideraciones de derechos fundamentales al momento de analizar este fenómeno explica en parte el problema. En general, el cumplimiento de las pensiones de alimentos ha sido abordado casi exclusivamente desde un punto de vista legal, con una lógica eminentemente civilista $\mathrm{y}$ con un marcado acento en aspectos procedimentales y/o administrativos.

Nos parece que un examen completo y actualizado de este tópico debe hacerse, por una parte, desde la perspectiva de la pensión de alimentos como un asunto de derechos fundamentales de niños, niñas y adolescentes (en adelante niños/as), directamente vinculado al derecho a la igualdad en las responsabilidades familiares de los adultos a cargo y, por otra, desde la perspectiva del derecho a la tutela judicial efectiva o acceso a la justicia en sentido amplio. Veamos cada uno de ellos.

\section{Pensiones de alimentos como un asunto de derechos fundamentales.}

Tradicionalmente la doctrina nacional ha considerado la prestación de alimentos como una obligación alimenticia de carácter civil. ${ }^{13}$ La doctrina más moderna, en cambio, ha ido asociando dicha prestación a los derechos fundamentales. ${ }^{14}$ Vodanovic, si bien señala que "el derecho de alimentos es uno de los medios a través del cual se hace efectivo el derecho a la vida", ${ }^{15}$ pero a la vez da cuenta que la regulación del "Código Civil no aborda la obligación de alimentos que pesa sobre el Estado, [pues] se limita a la relación alimenticia entre particulares". ${ }^{16}$

\footnotetext{
${ }^{13}$ Abeliuk, René. La filiación y sus efectos, Editorial Jurídica de Chile, Santiago, 2001, T. I, p. 397; GARRIDO, Carlos, Derecho de alimentos, análisis actualizado y formularios, Editorial Metropolitana, Santiago, 2020, p. 48; GoMEz DE LA TORRE, Maricruz, El sistema filiativo chileno, Editorial Jurídica de Chile, Santiago, 2007, p. 185; Troncoso, Hernán, Derecho de Familia, Thomson Reuters, Santiago, 2020, p. 359; Ramos, René, Derecho de Familia, Editorial Jurídica de Chile, Santiago, 2009, pp. 519547.

${ }^{14}$ Greeven, Nel, Derecho de alimentos como derecho humano y apremios para obtener el cumplimiento, Librotecnia, Santiago, 2018, p. 12; у SснміDт, Claudia, Del derecho alimentario familiar en la filiación, Editorial Punto Lex, Santiago, 2008, p. 139.

${ }^{15}$ Vodanovic, Antonio, Derecho de alimentos, Editorial Jurídica Conosur, Santiago, 1994, p. 3.

${ }^{16}$ Vodanovic, cit. (n. 15), p. 4.
} 
Independiente de las posturas mencionadas $\mathrm{y}$, desde la perspectiva del derecho a la tutela judicial efectiva, nos parece que en virtud de lo dispuesto en el artículo 27.4 de la Convención sobre los Derechos del Niño (en adelante $\mathrm{CDN}$ ), la pensión de alimentos es un asunto de derechos fundamentales. Ello, pues dicha norma establece el derecho del niño/a a que el Estado adopte las medidas apropiadas para asegurar el pago de la pensión ${ }^{17} \mathrm{y}$, por lo tanto, hace cargo del Estado la obligación de generar sistemas o mecanismos de cobro adecuados para el recupero de la pensión.

En la misma línea Nel Greeven sostiene la necesidad de recurrir a los principios, a la normativa internacional y a los tratados internacionales de derechos humanos para la interpretación e integración de este derecho con el fin de obtener el cumplimiento de los alimentos debidos. ${ }^{18}$

Esta obligación estatal, sin embargo, se desdibuja tratándose de los alimentos que se otorgan entre particulares que se encuentran unidos por vínculos familiares, tal vez porque aún se sigue considerando como un asunto privado de la familia. Cualquiera sea el motivo, lo cierto es que el pago de los alimentos ha sido entendido y aplicado como un asunto de naturaleza civil, como si los involucrados estuvieran en condiciones de igualdad para ejercer, promover y satisfacer sus derechos y como si el Estado no tuviera un papel relevante que jugar en este ámbito.

La CDN descarta la idea de que la obligación de pagar una pensión de alimentos pertenezca exclusivamente a la esfera privada. A partir de su vigencia, los Estados quedan facultados para intervenir cuando exista afectación del derecho de los niños/as que impida o dificulte el camino hacia el pleno y armonioso desarrollo de su personalidad o que impida prepararlo para una vida independiente y para el goce efectivo de los derechos de los que es titular. ${ }^{19}$

Con la ratificación de este tratado, el Estado chileno se ha comprometido a adoptar medidas especiales para resguardar el proceso de desarrollo de un niño/a al reconocer que "por su falta de madurez física y mental necesita

\footnotetext{
${ }^{17}$ Esta norma que se vincula con la regla general del artículo 4 de la CDN, cuya explicación el Comité de los Derechos del Niño la desarrolla en la Observación General $N^{\circ} 5$ que establece qué debe entenderse por las medidas adecuadas para garantizar los derechos del niño/a.

${ }^{18}$ Greeven, cit. (p. 14), pp. 28-38.

${ }^{19}$ Este texto incluye un resumen sobre la obligación del Estado no solo en situaciones excepcionales o de carácter tutelar, sino en situaciones ordinarias utiliza el concepto de un "garantizar un Estado útil para la infancia". https://www.corteidh.or.cr/tablas/r35198.pdf.
} 
protección y cuidados especiales incluso la debida protección legal" ${ }^{20} \mathrm{o}$, dicho en términos de la Convención Americana sobre Derechos Humanos (en adelante $\mathrm{CADH}$ ), el niño/a tiene derecho a que el Estado adopte "las medidas de protección que su condición de menor requiere". ${ }^{21}$

En cuanto al tipo de intervención estatal, es importante señalar que la CDN no se refiere a una modalidad en particular. Así, puede suceder que sea el propio Estado el que pague las pensiones; que se establezca un sistema administrativo para el cobro de ellas; que se organicen sistemas judiciales eficientes de cobro o bien que se establezca cualquier otra modalidad mixta o intermedia para lograr el pago de los alimentos. Pero, lo que no admite discusión es el hecho que, finalmente, es responsabilidad del Estado asegurar que las pensiones alimenticias sean pagadas.

Cabe preguntarse entonces, ¿cuál es el ámbito de responsabilidad que cabe al Estado en esta materia y cuál es su alcance?

El ámbito de responsabilidad del Estado en relación con la satisfacción de los derechos sociales está consagrado en varios artículos de la CDN. En particular, el artículo 26 establece quienes son los obligados a otorgar las prestaciones que forman parte del sistema de seguridad social de los niños/as, al señalar que deben concederse cuando corresponda. Y, para tal efecto, establece como criterio delimitador los recursos y situación del niño/a y los recursos y situación de las personas que sean responsables de su mantenimiento.

De este modo, creemos que el Estado deberá otorgar estas prestaciones cuando unos $\mathrm{u}$ otros no tengan los recursos o estos sean insuficientes para satisfacer el derecho a la seguridad social de los niños/as. Conforme al artículo 6, creemos que existen dos modalidades de otorgamiento de las prestaciones de seguridad social de los niño/as: una indirecta a cargo de los particulares y otra directa a cargo del propio Estado. De esta misma norma se desprende también el alcance de este deber, que incluye el derecho del niño/a a la vida, supervivencia, cuando señala que los Estados garantizarán este derecho en la "máxima medida posible".

Así, esta norma constituye un principio rector sobre el cual se vertebra el catálogo de derechos sociales la CDN contempla. ${ }^{22}$ Uno de ellos es el

\footnotetext{
${ }^{20}$ Opinión consultiva de la Corte IDH sobre Condición Jurídica de los Niños.

${ }^{21}$ Artículo 19 de la CADH.

${ }^{22}$ Los otros principios rectores son el principio de no discriminación, el principio del interés superior
} 
derecho de los niños/as a tener un nivel de vida adecuado para su desarrollo integral u holístico, consagrado en el artículo 27. Esta disposición reitera el criterio de definición de los ámbitos de responsabilidad del artículo 26, al señalar como los principales obligados a los adultos a cargo a prorrata de sus facultades económicas y al establecer la responsabilidad del Estado de adoptar medidas apropiadas para ayudar a los padres en esta tarea.

Si bien el artículo 27 no señala expresamente la participación directa del Estado en el otorgamiento de esta prestación ni tampoco cuál es el alcance de su deber de garantía, una interpretación sistemática de la CDN permite concluir que, además, de la responsabilidad de los adultos a cargo y la del propio Estado de adoptar las medidas apropiadas para ayudar a los padres, se incluye la responsabilidad de otorgar la prestación en forma directa a falta de recursos en el primer orden de obligados, una vez agotada su obligación de adoptar las medidas apropiadas para satisfacer el derecho en ese ámbito. Ello, debido a su rol de garante final del derecho a la seguridad social del artículo 26. Asimismo, una interpretación sistemática de la CDN permite concluir que la extensión de la responsabilidad de otorgar al niño/a un nivel de vida adecuado para el desarrollo, cuando le toca al Estado proveerlo, es en la máxima medida posible.

El artículo 27 se vincula con el artículo 18 de la CDN, pues de su lectura se desprende que los niños/as tienen el derecho a ser cuidados y proveídos en sus necesidades por ambos padres en proporción a los recursos económicos que cada uno posea. Desde esta perspectiva, el derecho a la coparentalidad también constituye una garantía que debe ser resguardada para asegurar que los niños/as satisfagan de mejor modo su derecho a tener un nivel de vida adecuado para su desarrollo integral. La responsabilidad conjunta de los adultos a cargo se vincula directamente el tema de la igualdad en la repartición de las responsabilidades familiares entre padre y madre. Esto porque para el adulto cuidador -habitualmente la madre- la vulneración de este derecho de sus hijos/as lo hará -en los hechos responsable- exclusivo de proveer sus necesidades materiales, lo que implica una sobrecarga injusta de sus funciones parentales y lo expone al riesgo de sufrir mayores niveles de pobreza. ${ }^{23}$

del niño y el principio de participación y de ser escuchado.

${ }^{23}$ Algunas cifras pueden revisarse en: Ministerio de Desarrollo Social y Familia, "Informe Desarrollo Social 2019”, 2019, pp. 21-24; documento disponible en línea: http://www.desarrollosocialyfamilia. 
A nuestro juicio, las normas antes reseñadas justifican que la pensión de alimentos de los niños/as debe ser considerada como un asunto de derechos fundamentales. La regulación alimenticia en el Código Civil no disminuye su categoría, pues como planteaba Vodanovic, lo que hace dicho código es limitarse a regular la prestación entre particulares. ${ }^{24}$

Por ello, que el referido código no haga alusión expresa a este punto o que no mencione el tipo de responsabilidad del Estado en esta materia no supone su inexistencia. Por el contrario, este silencio debe ser integrado con las normas de los tratados internacionales de derechos humanos que han sido ratificados por Chile, sin que el derecho interno pueda ser invocado como una excusa para dejar de hacer una interpretación coherente de sus normas. ${ }^{25}$

2. La ejecución de las resoluciones judiciales como parte integral del derecho a la tutela judicial efectiva o acceso a la justicia en sentido amplio.

Ya decíamos que los textos tradicionales de derecho procesal ponen escasa atención a la fase de ejecución de las resoluciones judiciales. En general, abordan esta temática desde una perspectiva exclusivamente procedimental, sin preguntarse por la lógica y objetivos que inspiran este tipo de procedimientos. ${ }^{26}$

Este enfoque contrasta con el desarrollo doctrinario de la ejecución en otras latitudes y, en particular, contrasta con el desarrollo jurisprudencial de la Corte Europea de Derechos Humanos (en adelante Corte EDH). Nicoló Trocker, en un trabajo pionero en esta materia, sostuvo que a partir de los fallos de este tribunal es posible construir una "nueva" noción del derecho de

gob.cl/storage/docs/Informe_de_Desarrollo_Social_2019.pdf, consultada: 13 de abril de 2021, pp. 2124; CASEN, "Caracterización de la Mujer en Chile", 2017, pp. 6, 10 y 11, disponible en línea: https:// minmujeryeg.gob.cl/wp-content/uploads/2020/03/Casen-2017-Mujer-Estudios.pdf consultada: 16 de abril de 2021.

${ }^{24}$ Vodanovic, cit. (n. 15), p. 4.

${ }^{25}$ Artículo 27 de la Convención de Viena sobre interpretación de los tratados.

${ }^{26}$ CAsarino, Manuel, Manual de Derecho Procesal, Editorial Jurídica de Chile, Santiago, 2005-2007, T. V, p. 43 y 44; Hoyos, Francisco, Temas fundamentales de Derecho Procesal, Editorial Jurídica de Chile, Santiago, 1987, p. 56 y 57; Lillo, Lenin, Manual de Juicio Ejecutivo, Ediciones Jurídicas de Santiago, Santiago, 2003, 158 p; CorreA, Jorge, Juicio Ejecutivo. Doctrina y jurisprudencia, Lexis Nexis, Santiago, 2003, y Orellana, Fernando, Manual de Derecho Procesal, Librotecnia, Santiago, 2008, T. III, p. 13. 
acceso a la justicia o tutela judicial efectiva, la cual -para los efectos de este trabajo- proponemos sea entendida como aquel derecho fundamental que garantiza a todas las personas el derecho a recurrir al órgano jurisdiccional y obtener una decisión fundada, congruente y sobre el fondo del asunto debatido que, en caso de ser favorable, pueda ser efectivamente cumplida ${ }^{27}$ - en virtud de la cual el cumplimiento de las resoluciones judiciales debe ser considerado como parte integrante del proceso. ${ }^{28}$

De acuerdo con la jurisprudencia de la Corte EDH, el derecho de las personas a presentar un reclamo o una demanda ante un tribunal sería ilusorio si el sistema no permitiera una implementación efectiva de las decisiones judiciales dictadas. ${ }^{29}$ Esta "nueva" noción de la tutela judicial efectiva -inclusiva de la dimensión de ejecución de las resoluciones judicialesimpone a los Estados tres estándares internacionales, que a continuación se desarrollan.

En la misma dirección algunos fallos de la Corte Interamericana de Derechos Humanos, a propósito de la exigencia de un recurso efectivo del artículo 25 del Pacto de San José de Costa Rica, han sostenido que no resulta suficiente la consagración legal de estos recursos si ellos no son idóneos para dotar eficacia a las resoluciones judiciales y que la ejecución de ellas forma parte del derecho a la tutela judicial efectiva. ${ }^{30}$

\footnotetext{
${ }^{27}$ Bordalí, Andrés, "Análisis crítico de la jurisprudencia del Tribunal Constitucional sobre el derecho a la tutela judicial efectiva", Revista Chilena de Derecho, 2011, Vol. 38, n 2, p. 322. En el medio nacional la delimitación conceptual de este derecho ha sido objeto de debate, no existiendo total coincidencia en su contenido y alcance. Para más información, véase: GarCía, Gonzalo; ConTreras, Pablo, "El derecho a la tutela judicial y al debido proceso en la jurisprudencia del Tribunal Constitucional chileno", Revista de Estudios Constitucionales, 2013, Vol. 11, № 2, pp. 229-282, y VArGAS, Macarena, "¿De qué hablamos cuando hablamos de acceso a la justicia? Un intento por iluminar el debate", en Machado, P.; Larroucau, J. (coords.), Estudios de Derecho Procesal, DER Ediciones, Santiago, 2019, pp. 233- 252.

${ }^{28}$ Trocker, Nicolo, "The Right to an Effective Enforcement of Civil Judgments and Orders: Lessons from the Case Law of the European Court of Human Rights", en: Stürner, R.; Kawano, M. (eds.), Comparative Studies on Enforcement and Provisional Measures, Mohr-Siebeck, Tübingen, 2011, pp. 115-139.

${ }^{29}$ Corte Europea de Derechos Humanos, sentencia de 19 de marzo de 1997, http://www.echr.coe.int/ ECHR/Homepage_EN, Caso Hornsby v. Grecia.

${ }^{30}$ Corte Interamericana de Derechos Humanos. Caso Mejía Idovro vs. Ecuador, sentencia de 5 de julio de 2011, parr. 105 y 106; Corte Interamericana de Derechos Humanos. Caso 5 pensionistas vs. Perú, sentencia de 28 de febrero de 2003, parr. 126; y Corte Interamericana de Derechos Humanos. Caso Furlan vs. Argentina, sentencia de 31 de agosto de 2012, parr. 209 a 211. En este último, la Corte IDH señala expresamente: "la efectividad de las sentencias depende de su ejecución" (parr. 209).
} 
Las tendencias jurisprudenciales de los tribunales internacionales unidas a los cambios legislativos en el derecho comparado han logrado reposicionar la ejecución civil como un tópico de interés en la protección de los derechos de las personas, dando pie a un paulatino pero creciente desarrollo doctrinario en los últimos años. ${ }^{31}$

a) Doctrina de la responsabilidad de los Estados y las obligaciones positivas.

El primero de estos estándares reposa sobre la base de que la protección y respeto de los derechos humanos no solo exige al Estado abstenerse de interferir en la esfera individual de las personas -lo que comúnmente conocemos como obligaciones negativas- sino que le exige también la adopción de medidas o acciones específicas para el respeto, protección, satisfacción y promoción de estos derechos -obligaciones positivas. ${ }^{32}$

Así, de acuerdo con la jurisprudencia de la Corte EDH, en materia de cumplimiento de las resoluciones judiciales, los Estados tienen la obligación positiva de organizar sistemas de ejecución asequibles, eficientes y de bajos costos para las partes y para el Estado, de modo que las decisiones judiciales sean cumplidas sin demoras indebidas. ${ }^{33}$

Por su parte, la Comisión Interamericana de Derechos Humanos (en adelante $\mathrm{CIDH}$ ) ha señalado que el derecho a un recurso judicial efectivo

\footnotetext{
${ }^{31}$ Pérez, Álvaro, Ejecución civil. Cómo lograr el cumplimiento del deudor, Editorial Astrea, Buenos Aires, 2019; SiLvA, Oscar, La transparencia patrimonial del deudor en la ejecución civil, Thomson Reuters, Santiago, 2014, 365 p; ARMENTA, Teresa, "Ejecución y medidas conminativas personales. un estudio comparado", Revista de Derecho Universidad Católica del Norte, 2015, Vol. 22, № 2, pp. 23-54; PÉreZ, Álvaro; NúÑEz, Raúl; VARgas, Macarena, Hacia una mejor ejecución civil, Thomson Reuters, Santiago, 2013, p. 224; KodEK, George E., "The impact of the European convention on human Rights and the fundamental liberties on enforcement practices", en: Andenas, M., Hess, B., Oberhammer, P. (eds.) Enforcement agency practice in Europe, BIICL, London, 2005, pp. 303-333; Orellana, Fernando, "Algunos aspectos del inicio del proceso de ejecución en el proyecto de Código Procesal Civil, en Justicia Civil: perspectivas para una reforma en la legislación chilena”, Cuadernos de Extensión Jurídica, Eds. Universidad de los Andes, Santiago, 2012; PAJIC, Natasa, "Avenues for enforcement and execution of judgments in the United States”, en: Van RheE, C.H.; Uzelac, A. (eds.), Enforcement and Enforceability. Tradition and reform, Intersentia, Antwerp-Oxford-Portland, 2010, pp. 237-250.

${ }^{32}$ VARGAS, cit. (n. 12), pp. 61 a 67.

${ }^{33}$ Corte Europea de Derechos Humanos, sentencia de 7 de junio de 2005, Caso Fuklev v. Ucrania, y 28 de noviembre de 2006, Caso Apostol v. Georgia.
} 
y el desarrollo de mecanismos adecuados de ejecución de las sentencias conforme al artículo 25 de la $\mathrm{CADH}$, conlleva la obligación del Estado de diseñar y consagrar normativamente un recurso eficaz, asegurar su debida aplicación por parte de las autoridades judiciales y construir e implementar mecanismos que garanticen la efectiva ejecución de las sentencias. ${ }^{34}$ Agrega que, "si las sentencias se tornan inoperantes por la falta de un diseño adecuado de los procedimientos judiciales, se constituye un típico caso de carencia de recurso judicial adecuado y efectivo para tutelar el derecho". ${ }^{35}$

b) Dimensión de eficacia de la ejecución de las resoluciones judiciales.

Este segundo estándar internacional de derechos humanos alude a la noción razonabilidad de los plazos. La Corte EDH ha sostenido que el requerimiento de plazos razonables es exigible al proceso completo, entendiéndolo como "un todo" que comprende, desde luego, la fase de ejecución. ${ }^{36}$ Ha señalado también que un proceso ha finalizado cuando termina la incertidumbre de la posición jurídica de las partes involucradas. ${ }^{37}$

Por otra parte, la Corte ha sostenido que los Estados no pueden excusarse de esta obligación aduciendo problemas de sobrecarga de los tribunales u otros para hacer cumplir las decisiones judiciales más allá de un plazo razonable, lo cual se examina en función de ciertos criterios jurisprudenciales, tales como, la complejidad del asunto, la conducta de las partes, la conducta de las autoridades y la importancia de lo que está en juego para los demandantes. ${ }^{38}$

\footnotetext{
${ }^{34}$ Comisión Interamericana de Derechos Humanos, "El acceso a la justicia como garantía de los derechos económicos, sociales y culturales. Estudio de los estándares fijados por el sistema interamericano de derechos humanos", 2007, http://www.cidh.org/pdf\%20files/ACCESO $\% 20$ A $\% 20$ LA\%20JUSTICIA\%20DESC.pdf, párr. 296, consultada: 27 de marzo de 2021.

${ }^{35}$ Ibíd., párr. 297.

${ }^{36}$ Corte Europea de Derechos Humanos, sentencia de 27 de junio de 2000, Caso Nuutinen v. Finlandia, parr. 109.

${ }^{37}$ Corte Europea de Derechos Humanos, sentencia de 26 de septiembre de 1996, Caso Di Pede v. Italia, para. 22 y sentencia de 23 de marzo de 1994, Caso Silva Pontes v. Portugal, parr. 29 y 30.

${ }^{38}$ Corte Europea de Derechos Humanos, sentencia de 13 de julio de 1983, Caso Zimmermann and Steiner v. Suiza; Corte Europea de Derechos Humanos, sentencia de 31 de marzo de 2005, Caso Matheus v. Francia; y Corte Europea de Derechos Humanos sentencia de 8 de diciembre de 2005, Caso Dumanovski v. República de Macedonia, parr. 45.
} 
c) Sistemas de ejecución "balanceados" entre acreedores y deudores.

Por último, este estándar exige a los Estados diseñar sistemas que se estructuren sobre la base de un adecuado equilibrio de los derechos de las partes: del acreedor a ejecutar su crédito de forma rápida y eficiente y del deudor a proteger correctamente sus intereses. ${ }^{39}$

Pero, la búsqueda de este balance no opera de la misma manera y con la misma intensidad en todas las áreas del derecho. Este equilibrio debe definirse en función de las capacidades de los litigantes y las particularidades de las obligaciones cuyo cumplimiento se exige. El legislador deberá realizar un ejercicio de ponderación de los derechos en juego sobre la base de los criterios de razonabilidad y proporcionalidad, según el tipo de conflictos que se trate.

Situados entonces en el ámbito de familia y, en particular en materia de alimentos, no es posible extrapolar en forma directa y sin cuestionamientos la lógica de la ejecución de asuntos civiles y comerciales. En el mundo de las obligaciones civiles se advierte una desigualdad entre litigantes, atendido el perfil que mayoritariamente estos tienen, principalmente acreedores son personas jurídicas vs. deudores personas naturales. ${ }^{40}$

En materia de pensiones de alimentos, en cambio, la balanza debe buscar un equilibrio distinto atendido el tipo de obligaciones en juego y el perfil de los involucrados. En este ámbito el Estado debe optar por un mecanismo que asegure el cumplimiento de las prestaciones alimentarias, dado el interés jurídico protegido, esto es, el derecho fundamental a la vida, supervivencia y desarrollo de niños/as y la igualdad en la repartición de las responsabilidades familiares de los adultos a cargo a la hora de diseñar un sistema de ejecución que aspira a ser eficiente y balanceado.

${ }^{39}$ Corte Europea de Derechos Humanos, sentencia de 21 de junio de 2012, Caso Olsby v. Suecia, parr. 50 .

${ }^{40}$ LiLlo, Ricardo, "La justicia civil en crisis. Estudio empírico en la ciudad de Santiago para aportar a una reforma judicial orientada hacia el acceso a la justicia (formal)", Revista Chilena de Derecho, 2020, Vol. 47, $\mathrm{N}^{\mathrm{o}}$ 1, p. 128 a 133, 138 y 139. A raíz de estas y otras consideraciones, en materia procesal civil se ha venido discutiendo con fuerza sobre la necesidad de equilibrar los derechos de los litigantes en los procedimientos ejecutivos, pues el diseño normativo nacional tiene una clara inclinación hacia el acreedor y posee escasos mecanismos de protección de los derechos del deudor. Salvo por la inembargabilidad de los bienes, el sistema procesal civil no cuenta con algunas instituciones procesales que sí están presentes en las legislaciones modernas en esta materia y que están orientadas a la búsqueda de un mayor balance de los derechos de las partes. Para más información véase: VARGAS, cit. (n. 12), p. 183. 
III. SEGUNDA RAZON: FALTA DE UN DISEÑO PROCESAL Y ORGANICO APROPIADO

Aunque cueste creerlo, la Ley 19.968 de Tribunales de Familia no contempla un procedimiento especial para la fase de ejecución de las resoluciones judiciales para ninguna de las materias que forman parte de su competencia. Solo es posible encontrar en las normas supletorias de esta ley una remisión a las disposiciones comunes a todo procedimiento del Código de Procedimiento Civil (en adelante CPC), haciendo aplicable entonces el procedimiento ejecutivo que allí se contempla. ${ }^{41}$

Esta remisión plantea una serie de inconvenientes que obstaculizan el pago de las pensiones de alimentos por varias razones. En primer lugar, porque el CPC es un código diseñado para resolver los conflictos civiles y comerciales entre particulares. Dichos asuntos tienen una fisonomía muy distinta a los conflictos de familia, que, entre otros aspectos, se caracterizan por la permanencia de las relaciones de los involucrados, un fuerte componente emocional y porque las consecuencias de las decisiones judiciales atañen directamente a niños/as, aunque ellos no sean los litigantes del caso.

En segundo lugar, porque el CPC contiene un sistema de ejecución respecto del cual existe consenso -prácticamente unánime en la doctrina nacional- de que se trata de un procedimiento que urge reformar. ${ }^{42}$ Tanto es

41 “Artículo 27.- Normas supletorias. En todo lo no regulado por esta ley, serán aplicables las disposiciones comunes a todo procedimiento establecidas en el Código de Procedimiento Civil, a menos que ellas resulten incompatibles con la naturaleza de los procedimientos que esta ley establece, particularmente en lo relativo a la exigencia de oralidad. En dicho caso, el juez dispondrá la forma en que se practicará la actuación".

${ }^{42}$ Silva, J.P., García, J.F., LetURIA, F.J. (eds.), Justicia civily comercial. Una reforma pendiente: bases para el diseño de la reforma procesal civil, Instituto Libertad y Desarrollo, Universidad Autónoma de Madrid, Santiago, 2006, p. 813; VARGAS, Macarena, "Reflexiones en torno a la figura del oficial de ejecución”, en Leturia, F.J. (ed.), Justicia Civil y Comercial: Una Reforma ¿Cercana?, Ediciones LYD, Santiago, 2011, pp. 471-488; Pontificia Universidad Católica de Valparaíso, "Informe Final. Diseño de un Modelo de Oficial de Ejecución", Valparaíso, 2012.; Pérez Ragone, Álvaro, "Derecho a la tutela ejecutiva del crédito: entre mitos, temores y realidad", en: Aguirrezabal, M. (ed.), Cuadernos de Extensión Jurídica, Nㅜ 23, Eds. Universidad de los Andes, Santiago, 2013; Ministerio de Justicia, "Informe final Panel de Expertos para la creación de un modelo orgánico de oficial de ejecución", 2013, http://rpc.minjusticia.gob.cl/media/2013/07/Informe-Final-Modelo-Organico.pdf, consultada: 19 de marzo de 2021; Palomo, Diego, "Reformas de la ejecución civil y del proceso monitorio: la apuesta chilena por la tutela judicial efectiva y el derecho de acceso a un debido proceso", Estudios Constitucionales, 2014, Nº12, pp.475-502. 
así que, el Proyecto de Ley de Nuevo Código Procesal Civil, presentado en 2012 durante el primer gobierno del presidente Sebastián Piñera proponía una reforma significativa al sistema vigente. ${ }^{43} \mathrm{Si}$ bien el libro que regulaba dichos procedimientos fue, dos años más tarde, retirado de la discusión parlamentaria, ${ }^{44}$ nadie duda de que el modelo actual debe ser objeto de revisión y reforma.

Por último, en tercer lugar, porque la remisión que la Ley de Tribunales de Familia hace al CPC no es al Libro III donde se regulan los procedimientos ejecutivos, sino que al Libro I donde se regulan las disposiciones comunes a todo procedimiento. Si bien dicho libro regula la ejecución de las resoluciones a propósito del procedimiento ejecutivo de cumplimiento incidental, cuyas normas serían aplicables en sede familiar, ellas mismas vuelven a reenviar a las reglas del Libro III, antes mencionado. ${ }^{45}$

Ahora bien, es necesario señalar que la Ley 14.908 sobre abandono de familia y pago de pensiones de alimentos contempla una norma referida a la ejecución. Pero ella no contiene un procedimiento ejecutivo propiamente tal, sino que se limita a otorgar mérito ejecutivo a las resoluciones que decretan alimentos o que aprueban una transacción y establece las reglas de competencia a seguir. ${ }^{46}$

Todas estas consideraciones hacen que, como lo señalan Greeven y Orrego, se trate de una normativa "arcaica e incompleta que genera múltiples interrogantes en su aplicación". ${ }^{47}$

Desde el punto de vista orgánico, la Ley de Tribunales de Familia contempla la figura de unidades administrativas, entre las cuales se encuentra una destinada al cumplimiento. ${ }^{48}$ A ella le compete desarrollar "las gestiones necesarias para la adecuada y cabal ejecución de las resoluciones judiciales en el ámbito familiar, particularmente de aquellas que requieren de cumplimiento sostenido en el tiempo". ${ }^{49}$

\footnotetext{
${ }^{43}$ Boletín 8197-07, Proyecto de Ley que crea el Nuevo Código Procesal Civil, 12 de marzo de 2012.

${ }^{44}$ En Sesión 21ª/362 de la Cámara de Diputados, el 7 de mayo de 2014.

${ }^{45}$ Artículo 235 Código de Procedimiento Civil.

${ }^{46}$ Art. 11, Ley 14.908.

${ }^{47}$ Greeven, Nel; OrRego, Juan Andrés, Alimentos y su ejecución en materia de familia, DER Ediciones, Santiago, 2018, p. 1.

${ }^{48}$ Artículo 2, Ley de Tribunales de Familia.

${ }^{49}$ Artículo $2 \mathrm{~N}^{\circ} 5$ LTF: "Cumplimiento, que, dada la particular naturaleza de los procedimientos
} 
Luego de eso, la Ley $\mathrm{N}^{\circ} 19.968$ no dice nada más. ${ }^{50}$ En la práctica ello ha dado pie a que el cumplimiento sea percibido como un aspecto que compete exclusivamente a la gestión interna de los tribunales. ${ }^{51}$ En ese escenario, los administradores/as de los tribunales de familia han organizado el trabajo de las distintas unidades bajo criterios de gestión, basado en la comprensión práctica que ellos tienen del procedimiento de cumplimiento, sin incluir -por este motivo- cuestionamientos a las normas procesales ni a la aplicación e interpretación que de ellas se hace.

Ello ha influido en la manera como se despliega el procedimiento ejecutivo, porque la gestión en su tarea de resolver el problema del incumplimiento paulatinamente ha ido consolidando prácticas judiciales, que pueden no estar orientadas a conseguir la efectividad de los derechos de las partes. Entender que el cumplimiento atañe únicamente a la administración es creer que una mejor gestión necesariamente conllevará a un mejor resultado. Y si bien en términos generales esta apreciación podría ser correcta creemos que ella debe ponderar otros factores, como la calidad y la oportunidad de la respuesta ${ }^{52}$ y debe ser evaluada desde parámetros de derechos fundamentales.

Una manifestación de que el cumplimiento corresponde a la administración se advierte con la creación de la Unidad Centralizada de Cumplimiento (en adelante UCC). Ella deriva del expediente AD-702-06 de la Corte Suprema de fecha 14 de noviembre de 2008, suscrita por el entonces presidente de la Corte Suprema y basada en el trabajo llevado a cabo por los administradores de los cuatro Tribunales de Familia de Santiago, todo ello con el respaldo del Consejo Superior de la Corporación Administrativa del

establecidos en esta ley, desarrollará las gestiones necesarias para la adecuada y cabal ejecución de las resoluciones judiciales en el ámbito familiar, particularmente de aquellas que requieren de cumplimiento sostenido en el tiempo".

${ }^{50}$ Con todo, aun cuando exista legislación en esta materia se suscitan problemas de interpretación y de aplicación. Un ejemplo de ello se explica en un trabajo sobre la forma en que los tribunales españoles se han hecho cargo de la oposición a la ejecución por el cambio de las circunstancias respecto del momento en que se fijó la pensión alimenticia. Véase: NEVADO, Juan José, "La oposición a la ejecución de pensiones alimenticias. referencia a la posibilidad de extinción de la pensión alimenticia en el procedimiento ejecutivo", Actualidad Jurídica Iberoamericana, 2019, № extra, 10, № 2, pp. 736-745.

${ }^{51}$ Pérez, cit. (n. 11), p. 65.

${ }^{52}$ Fuentes, Claudio; García, Ramón; Silva, Rodrigo, Gestión y control judicial de la litigación: case management, DER Ediciones, Santiago, 2021, pp. 34 a 37. 


\section{Poder Judicial. ${ }^{53}$}

Nace con el objetivo de anticiparse al colapso que se preveía venir producto del cierre de la judicatura de menores y del incremento de las causas en el nuevo sistema de justicia de familia de esos años. Así, se buscaba estandarizar los procedimientos de ejecución para dotarlos de mayor agilidad. ${ }^{54} \mathrm{Si}$ bien hubo avances en la obtención de esta finalidad, aún se mantiene el reclamo público por la ineficacia de la ejecución de las pensiones de alimentos; ineficacia que, a propósito del retiro del $10 \%$ de los fondos previsionales, se ha hecho más evidente.

\section{TERCERA RAZÓN: NO CONTAMOS CON DATOS PARA DIAGNOSTI- CAR EL PROBLEMA Y DISEÑAR SOLUCIONES}

Si la ausencia de un enfoque de derechos fundamentales y escasas normas sobre ejecución en materia de familia constituyen explicaciones plausibles sobre el problema del incumplimiento, la escasez de evidencia empírica constituye un elemento adicional para comprender la complejidad de este fenómeno.

En la actualidad la información estadística a cargo del Poder Judicial permite establecer, entre otros aspectos, el número de liquidaciones de deudas, apremios y retenciones que se efectúan. ${ }^{55}$ Pero, no se recaba información sobre el cumplimiento o incumplimiento de las pensiones de alimentos decretadas ${ }^{56}$, del resultado obtenido con las medidas dictadas ni de las características de los alimentantes y alimentarios/as.

La información recopilada se focaliza casi exclusivamente a aspectos propios de la gestión administrativa, lo que ha implicado la ausencia de registro de otras variables que permitirían medir el funcionamiento del proceso de ejecución de manera más completa y comprehensiva. Ello contrasta con lo dispuesto por el Comité de los Derechos del Niño que plantea la exigencia de recopilar datos "suficientes y fiables sobre los niños, desglosados para poder determinar si hay discriminaciones o disparidades

\footnotetext{
${ }^{53}$ PÉrez, cit. (n. 11), p. 25.

54 PÉrez, cit. (n. 11), p. 27.

55 Dirección de Estudios de la Corte Suprema, cit. (n. 4).

${ }^{56}$ Dirección de Estudios de la Corte Suprema, cit. (n. 4), p. 22.
} 
en la realización de sus derechos" 57 respecto de las medidas que se adopten en su beneficio para satisfacer, entre otros, el principio rector de vida supervivencia y desarrollo. ${ }^{58}$

En el caso chileno son muy pocos los estudios de campo o investigaciones con datos estadísticos que permiten aproximarse a este fenómeno. Si bien ellos han entregado importantes insumos, se trata de iniciativas aisladas, preferentemente universitarias y que no responden a una lógica sistemática de levantamiento de información que habiliten al Poder Judicial -y otros actores- a tomar decisiones en base a la evidencia.

Uno de ellos es el efectuado en 2011 por el Centro UC de la Familia de la Pontificia Universidad Católica de Chile, que examinó las causas tramitadas en tribunales de familia en la Región Metropolitana entre los años 2008 a $2011 .^{59}$ Entre otros resultados, este estudio muestra que la mayoría de las solicitudes de cumplimiento se efectúa dentro de las dos primeras semanas del otorgamiento de alimentos definitivos (21.54\%), lo que, sin embargo -tal como allí se indica- corresponde a la liquidación del monto de los alimentos provisorios, pues los primeros aún no se han devengado. ${ }^{60} \mathrm{Un}$ año después el porcentaje de incumplimiento baja levemente, alcanzando al $16.92 \%{ }^{61}$ Este estudio muestra también que la medida de apremio más solicitada es el arresto, pero a la vez es la menos otorgada por los tribunales. ${ }^{62}$ Sus efectos, además, son relativos, pues en el 69\% de los casos el deudor no es habido. ${ }^{63}$ Otro dato interesante es que el $25 \%$ de los demandados se opone a la liquidación de la deuda. ${ }^{64}$

Un segundo estudio de carácter cualitativo empírico-exploratorio -efectuado en el 2014 también por la Pontificia Universidad Católica de Chile- da cuenta de una percepción generalizada sobre la facilidad que

\footnotetext{
${ }^{57}$ Observación General N5 5 del Comité de los Derechos del Niño. El numeral 48 señala: "La reunión de datos suficientes y fiables sobre los niños, desglosados para poder determinar si hay discriminaciones o disparidades en la realización de sus derechos, es parte esencial de la aplicación".

${ }^{58}$ Ibíd.

${ }^{59}$ Centro UC de la Familia, "Informe Final sobre estudio, análisis y propuestas en materia de procedimiento y cumplimiento en el pago de las pensiones alimenticias", PUC, Santiago, 2011, p. 51.

${ }^{60}$ Centro UC de la Familia, cit. (n. 59), p. 51.

${ }^{61}$ Ibíd., p. 51.

${ }^{62}$ Centro UC de la Familia, cit. (n. 51), p. 53.

${ }^{63}$ Ibíd., p. 53.

${ }^{64}$ Centro UC de la Familia, cit. (n. 51), p. 53.
} 
tienen los alimentantes para eludir el pago de la pensión de alimentos. ${ }^{65}$ Ello se debería a la poca eficiencia de las medidas de apremio y a la demora en la tramitación de las solicitudes de los alimentarios/as. ${ }^{66}$ Dentro de los problemas específicos allí detectados destacan aquellos que se suscitan a propósito de las liquidaciones y reliquidaciones de las deudas, la no reajustabilidad del monto de la pensión (el retraso no genera intereses) y el abuso en la solicitud de suspensiones de pago, por mencionar solo algunos. ${ }^{67}$

Por último, el estudio más reciente data del 2018 y aporta interesante información de campo. Se trata de una investigación empírica realizada en el marco de una tesis de magister, cuyo objetivo fue indagar en el problema del cumplimiento en los tribunales de familia de Santiago. ${ }^{68}$ Haciendo uso de metodología cualitativa, se buscó comprender en profundidad como los actores judiciales perciben y dan sentido a sus acciones en este ámbito. ${ }^{69}$ Entre los muchos datos recopilados, algunos de ellos ilustran las particularidades que presenta esta problemática y la multiplicidad de factores que allí están envueltos.

Por ejemplo, en relación con la duración del procedimiento para la obtención de una medida de apremio personal (arresto o arraigo), el estudio muestra que este se extiende en promedio 35 días, es decir, poco más de un mes.

Ello se explicaría por una serie de pasos que deben ser realizados por el alimentario/a para obtener una orden de apremio; pasos que no se encuentran regulados en la ley ${ }^{70}$ sino que son el resultado de la práctica de nuestros tribunales de familia, ${ }^{71}$ a saber: (a) el alimentario/a solicita la medida de apremio personal; (b) el tribunal ordena liquidar la deuda; (c) se procede a

\footnotetext{
${ }^{65}$ Centro UC Políticas Públicas, "Propuestas para Chile. Capítulo X: Pago de pensiones alimenticias: avanzando hacia una real y eficiente tutela de la infancia y la familia", 2014, https://politicaspublicas. uc.cl/wp-content//uploads/2015/06/Propuestas-para-Chile-2014_Cap\%C3\%ADtulo-10_Valdivia.pdf, consultada: 6 de abril de 2021.

${ }^{66}$ Centro UC Políticas Públicas, cit. (n. 65), p. 314.

${ }^{67}$ Centro UC Políticas Públicas, cit. (n. 65), p. 315.

${ }^{68}$ Pérez, cit. (n. 11).

${ }^{69}$ Pérez, cit. (n. 11), p. 1.

${ }^{70} \mathrm{Tal}$ como se menciona al inicio del apartado anterior, la legislación procesal de familia no cuenta en forma expresa con un procedimiento de ejecución, lo que obliga al intérprete a construir sus fases a partir de la supletoriedad que asume el CPC en esta materia.
}

${ }^{71}$ Pérez, cit. (n. 11), p. 74 a 79. 
la liquidación de la deuda por parte de la Unidad de Cumplimiento; (d) el tribunal dicta una resolución poniendo la liquidación en conocimiento de las partes, para posibles objeciones por el plazo de 3 días (e) transcurridos los 3 días, el alimentario/a debe reiterar el reclamo y (f) el tribunal dicta una resolución que despacha la orden de arresto o arraigo solicitada.

Si se observa hay, a lo menos, cinco pasos que cumplir antes de que se dicte la orden de apremio. A ellos se pueden sumar muchos otros, dependiendo de la actividad que desarrollen las partes. Por ejemplo, si en el intertanto estas llegan a un acuerdo de pago o si una de ellas objeta la liquidación, ello incidirá directamente en la duración de la tramitación de la medida solicitada. ${ }^{72}$

Otro aspecto que este estudio revela es el efecto de los recursos de amparo deducidos por los alimentantes una vez dictada una medida en su contra y cómo ello desincentiva el despacho de las órdenes de arresto. La estrategia legal basada en el derecho a la libertad personal del deudor logra ser acogida por los tribunales de familia, pese a fundarse en pagos parciales y muchas veces de sumas irrisorias en relación con el monto adeudado. Ello moviliza rápidamente a los actores judiciales a acoger las solicitudes de alzamiento de la orden dictada, incluso en un par de horas. ${ }^{73} \mathrm{Si}$ bien la protección del derecho a la libertad personal del alimentante es un aspecto positivo tanto para el afectado como para el sistema judicial en su conjunto, llama la atención la gran diferencia de tiempo que toma obtener una medida de apremio en comparación con el tiempo que demora alzarla (en promedio un mes versus algunas horas).

Todo parece indicar que al interior de la cultura judicial la afectación de la libertad del deudor es un aspecto prioritario por sobre incluso del derecho de alimentos de niños/as y el derecho a la igual repartición de las responsabilidades familiares.

Con todo, si bien los datos de este y otros estudios han contribuido a la delimitación general del asunto, las decisiones destinadas a mitigar (e idealmente a resolver) el problema del incumplimiento requiere de una recopilación periódica de información, atendido el carácter dinámico y evolutivo del derecho de familia y de su ejercicio.

Requerimos, además, de una recopilación de la información levantada

\footnotetext{
${ }^{72}$ Ibid.

${ }^{73}$ Pérez, cit. (n. 11), p. 51.
} 
en función de criterios e indicadores previamente definidos. Entre otros aspectos, parece urgente contar con información, al menos, sobre tres puntos claves. Primero, sobre la efectividad de las medidas de apremio dictadas, esto es, saber cuáles de ellas son más eficaces y dónde están los “cuellos de botella" en los procedimientos realizados para su obtención. Segundo, sobre el perfil de los deudores de alimentos y las razones que subyacen a su comportamiento (cuántos buscan evadir sus responsabilidades y cuántos incumplen por otras razones, como enfermedad o cesantía). Tercero, es fundamental conocer el porcentaje de incumplimiento de las pensiones de alimentos, pues -tal como se mencionó al inicio- la fuente original de donde surge la cifra del $84 \%$, difundida copiosamente en los medios de comunicación $^{74}$ resulta difícil de rastrear y ha sido discutida en cuanto a su origen.

Un artículo elaborado por la Dirección de Estudios de la Corte Suprema (en adelante DECS) de diciembre del 2020 se refiere a este punto. ${ }^{75}$ Usando una metodología mixta consistente en entrevistas a actores claves del sistema de justicia familiar y un análisis de datos estadísticos plantea que, de acuerdo con la información con que esta repartición cuenta, "no es posible identificar exactamente cuál es el porcentaje -en relación al total de causas- de incumplimientos en materia de obligaciones de alimentos". ${ }^{76}$ Se indica que se ha procedido "mediante información indiciaria disponible, a identificar el nivel de incumplimiento de obligaciones alimentarias". ${ }^{77}$ debido a que el Sistema Informático de los Tribunales de Familia (en

\footnotetext{
${ }^{74}$ Algunos ejemplos de ello pueden verse en: Cortez-Monroy , cit. (n. 2); Noticia: "El 84\% de las pensiones se encuentran impagas: ¿por qué los chilenos no pagan la pensión alimenticia a sus hijos?", La Tercera, 2020, https://www.latercera.com/que-pasa/noticia/el-84-de-las-pensionesse-encuentran-impagas-por-que-los-chilenos-no-pagan-la-pension-alimenticia-a-sus-hijos/ R35K3FMPGNDZ5DR4VWGWGAF5SU/, consultada: 27 de abril de 2021; Noticia: "Ministro de Desarrollo Social: "E1 84\% de las pensiones alimenticias no se pagan", ADN Radio, 2020, https://www. adnradio.cl/nacional/2020/03/10/ministro-de-desarrollo-social-el-84-de-las-pensiones-alimenticias-nose-pagan.html, consultada: 27 de abril de 2021; Noticia: “Abogada de familia: Un 84\% de los papás no paga la pensión de alimentos", Radio Concierto, 2020, https://www.concierto.cl/2020/03/abogada-defamilia-un-84-de-los-papas-no-paga-la-pension-de-alimentos/, consultada: 27 de abril de 2021; Noticia: "El pago de la pensión de alimentos en Chile, Diario Concepción, https://www.diarioconcepcion.cl/ editorial/2020/08/12/el-pago-de-la-pension-de-alimentos-en-chile.html, consultada: 27 de abril de 2021.

${ }^{75}$ Dirección de Estudios de la Corte Suprema, cit. (n. 4).

${ }^{76}$ Dirección de Estudios de la Corte Suprema, cit. (n. 4), p. 30.

${ }^{77}$ Dirección de Estudios de la Corte Suprema, cit. (n. 4), p. 114.
} 
adelante SITFA) no permite obtenerlo. ${ }^{78}$ Luego se menciona que, tomando como indicador la dictación de una medida compulsiva se estima que el nivel de incumplimiento de las pensiones de alimentos se encuentra "en torno al $30 \% " .79$

Consideramos que la diferencia en las cifras existentes sobre incumplimiento $-84 \%$ y $30 \%$ - evidencian un serio problema en la recolección de la información y una cierta desorientación institucional sobre los objetivos de la fase cumplimiento y los indicadores necesarios para levantar información en esta materia. En efecto, no solo es que el SIFTA tenga falencias -tal como concluye dicho estudio ${ }^{80}$ - sino que todo parece indicar que la generación de información sobre el pago de las pensiones no fue considerado a la hora de diseñar los indicadores de medición del quehacer de los tribunales de familia. Implícitamente parece asumirse que el cumplimiento/incumplimiento no formaría parte de la tarea jurisdiccional $\mathrm{y}$, por ende, no atañe al derecho acceso a la justicia o tutela judicial efectiva.

Por otra parte, el referido artículo sostiene que -si bien no existen estudios exploratorios que permitan verificar cómo funciona el sistema judicial chileno en esta materia- hay una percepción generalizada de su insuficiencia. ${ }^{81}$ También indica que la inefectividad de la ejecución alimenticia encuentra su origen en un problema cultural y legal derivado del modo en que se han integrado los vacíos legales y se han interpretado y aplicado las normas existentes al caso concreto. ${ }^{82}$

\section{CUARTA RAZÓN: LA CULTURA LEGAL Y SUS EFECTOS EN LAS PRÁCTICAS DE JUECES/AS Y FUNCIONARIOS/AS JUDICIALES}

Una cuarta razón que explicaría el fenómeno del incumplimiento se vincula con las prácticas judiciales. Es decir, con la forma en que los actores judiciales "hacen la cosas" y las comprensiones que dan sentido a tales acciones.

\footnotetext{
${ }^{78}$ Dirección de Estudios de la Corte Suprema, cit. (n. 4), p. 28.

${ }^{79}$ Dirección de Estudios de la Corte Suprema, cit. (n. 4), p. 30.

${ }^{80}$ Dirección de Estudios de la Corte Suprema, cit. (n. 4), p. 28.

${ }^{81}$ Dirección de Estudios de la Corte Suprema, cit. (n. 4), p. 18.

${ }^{82}$ Dirección de Estudios de la Corte Suprema, cit. (n. 4), p.117.
} 
Ponemos acento en este punto, pues como señala Alda Facio, el derecho no solo se constituye por las normas formalmente promulgadas, sino también por aquellas surgidas como consecuencia del proceso de aplicación e interpretación de las leyes junto con las reglas informales "que determinan quien, cuándo y cómo se tienen acceso a la justicia y que derechos tiene cada quien". 83

A continuación, se mencionarán tres aspectos prácticos que no buscan analizar los problemas o "cuellos de botella" de la fase de cumplimiento, como lo han hecho los estudios mencionados previamente, sino que buscan identificar las lógicas que están detrás del actuar de los operadores del sistema.

\section{Libertad personal del deudor. Preeminencia de los intereses del deudor} por sobre los intereses de los alimentarios

Una de las razones que justifican estas prácticas es lo que se ha denominado "la presencia hegemónica de la libertad personal del deudor" 84 por sobre la afectación de los derechos de los otros involucrados/as en estos procesos. Este dato -recogido en el estudio de 2018- es corroborado en el 2020 por la DECS cuando señala que en la práctica judicial existe una priorización del derecho a la libertad de circulación de los alimentantes por sobre los derechos de los alimentarios/as. ${ }^{85}$

Ello se puede observar en algunas sentencias de segunda instancia donde los intereses que el sistema cautela son, en mayor medida, los del alimentante. ${ }^{86}$ En efecto, dichos fallos relativos a amparos de resoluciones que disponen el apremio personal parecen no considerar todos los intereses que están en juego y parecen estimar la orden de arresto como una anomalía del proceso de ejecución, perdiendo de vista que acoger un amparo repercute no solo en la posibilidad de obtener el recupero de la pensión de alimentos

\footnotetext{
${ }^{83}$ FACIO, Alda, "Con los lentes del género se ve otra justicia”, El otro derecho (Bogotá), 2002, № 28 , pp. 85-102.

${ }^{84}$ Pérez, cit. (n. 11), p. 57.

${ }^{85}$ Dirección de Estudios de la Corte Suprema, cit. (n. 4), p. 120.

${ }^{86}$ A modo de ejemplo, véase: Corte de Apelaciones de Santiago, 18 de noviembre de 2021, Rol Amparo 5361-2021; Corte de Apelaciones de Santiago, 17 de diciembre de 2020, Rol Amparo 2922-2020; Corte de Apelaciones de Santiago, 24 de noviembre de 2020, Rol Amparo 2694-2020; Corte de Apelaciones de Santiago, 1 de julio de 2020, Rol Amparo 1489-2020.
} 
en el caso particular, sino que en la efectividad de la medida en general.

Resulta paradójico que el proceso de ejecución diseñado para satisfacer los derechos de los alimentarios/as termine siendo la forma de cautelar los derechos de los alimentantes que han sido objeto de una medida de apremio. En efecto, los pasos destinados a obtener tal medida -descritos en el acápite anterior y, que como mencionamos, no están regulados legalmente- parecen haber sido establecidos con el fin de asegurar el correcto despacho de una orden de apremio más que asegurar el pago de las pensiones adeudadas. ${ }^{87}$

Así, todos los esfuerzos de los actores judiciales parecen estar dirigidos a "resolver" la situación del deudor apremiado (habitualmente un varón) y no a obtener el pago de las pensiones de alimentos en favor de los alimentario/ as y sus cuidadores (habitualmente niños/as y sus madres). ${ }^{88}$ Todo indica que ni el derecho de alimentación del niño/a, ni el interés superior de estos ni tampoco el derecho a la igualdad logran aminorar esta forma de comprender los objetivos del proceso de ejecución de las pensiones impagas.

Pareciera existir una especie de orden de prevalencia o de género a la hora de resolver este tipo de situaciones, una jerarquía que ha estado, desde luego, completamente invisibilizada. Se trata de prácticas judiciales que olvidan la variable de desigualdad estructural que se encuentra a la base de estos asuntos. La cultura legal refuerza estas arraigadas prácticas de tal forma que las gestiones realizadas en la fase de cumplimiento llegan a normalizarse y a estimarse como naturales e, incluso, como justas por parte de los actores judiciales.

Sin embargo, no lo son. Y ello es así no solo porque tales pasos o trámites no encuentran consagración legal, sino porque su uso produce una vulneración grave de los derechos de los niños/as que están detrás de estas solicitudes de apremio, contribuyendo a la feminización de la pobreza o, en términos de Kimmel, a la "masculinización de la riqueza" y, además, a la "masculinización de la irresponsabilidad". ${ }^{89}$

\footnotetext{
${ }^{87}$ Pérez, cit. (n. 11), p. 57 a 64.

${ }^{88}$ Pérez, cit. (n. 11), p. 63.

${ }^{89}$ Kimmel, Michael, Hombres (blancos) cabreados la masculinidad al final de una era, Editorial Barlin Libros, Valencia, 2014, p. 229.
} 


\section{Liquidación de las deudas}

Decíamos antes que no existe norma legal que obligue a los tribunales de familia a realizar una liquidación de la deuda para despachar una medida de apremio. ${ }^{90}$ Sin embargo, nadie duda que este trámite debe realizarse con el fin de establecer el monto debido de manera indubitada para que el deudor no vea afectada su libertad personal.

Ahora bien, los cuestionamientos a la liquidación no se refieren a este trámite en sí mismo, sino fundamentalmente al tipo de notificación a través de la cual se informa a las partes el monto adeudado. Como no hay regulación legal acerca de la liquidación, tampoco hay regulación sobre la forma en que debe comunicarse la resolución que la contiene.

En la práctica ello ha dado pie a que se utilicen distintos tipos de notificaciones (por cédula, por el estado diario, por correo electrónico e incluso personalmente), lo que contribuye a crear una sensación de incertidumbre en la tramitación de estas medidas.

Con todo, de acuerdo con el artículo de la DESC de 2020, la notificación por cédula resulta ser la forma más frecuente. ${ }^{91}$ Su uso reposa en la necesidad de dar a conocer los resultados de esta gestión con el fin de que las partes tomen conocimiento de ella y puedan objetarla, especialmente el deudor de los alimentos. Nuevamente se observa una primacía implícita de los derechos de los alimentantes por sobre los de los alimentarios/as. Si bien compartimos la necesidad de notificar a las partes de esta gestión, hacerlo por cédula parece olvidar que, en su momento, el alimentante fue notificado de una sentencia que lo condena al pago de los alimentos o que concurrió con su voluntad a un acuerdo donde se fijó la pensión alimenticia. Parece olvidar también que el deudor no puede menos que saber si ha pagado o no, por lo que, a nuestro juicio, bastaría con notificarlo por el estado diario o por correo electrónico, siendo su deber informar al tribunal el cambio de dirección electrónica, en su caso.

Por otra parte, la liquidación de la deuda, como se señaló anteriormente, es uno de los trámites que más tiempo demora y ello se explica porque esta tarea es realizada caso a caso y en forma manual por funcionarios/as judiciales llamados "liquidadores". Como es dable imaginar lo anterior supone una

\footnotetext{
${ }^{90}$ Greeven y Orrego, cit. (n. 47), p. 38.

${ }^{91}$ Dirección de Estudios de la Corte Suprema, cit. (n. 4), pp. 59 y 118.
} 
gran carga de trabajo para las unidades de cumplimiento, atendido el alto número de solicitudes de apremios personales que se reciben. ${ }^{92}$

Se entiende, además, que la liquidación debe ser realizada solo respecto de aquellas causas en las cuales se pide la ejecución por parte de los alimentarios/as (el énfasis es nuestro). Lejos está la posibilidad de que este trámite pueda realizarse de oficio por el tribunal, tal como lo dispone el artículo 14 de la ley 14.908. La respuesta inmediata a un planteamiento de esta naturaleza sería negativa y estaría fundada en la dificultad que deriva del volumen de casos que manejan los tribunales de familia en materia de pensión de alimentos.

Si bien entendemos que una decisión como esa significaría un aumento importante en la carga de trabajo de los tribunales de familia, no hacerlo vuelve a relegar a un segundo plano el derecho de acceso a la justicia o tutela judicial efectiva de los alimentarios/as sobre la base de criterios de gestión administrativa, donde el procedimiento se vuelve lo más importante (algo así como "las formas por las formas"), sin poner mayor atención en los derechos de niños/as y cuidadores/as que están en juego.

Creemos que, si la mayoría de las pensiones de alimentos se pagan a través de las libretas de ahorro del BancoEstado, ¿por qué negarse a que las cartolas de estado de cuenta se incorporen regularmente a los procesos de alimentos y se realice una liquidación automatizada de la deuda, en caso de ser necesario?

Desde luego, esto requeriría de un importante esfuerzo de coordinación interinstitucional entre el Poder Judicial y el BancoEstado, pero ello se podría enmarcar en el convenio que existe desde hace varios años entre ambas instituciones. ${ }^{93}$ En efecto, en el año 2016 se firmó un convenio destinado a "modernizar la forma de operar de los tribunales de familia y mejorar la atención de los clientes usuarios de libretas de ahorro de pagos de pensiones". ${ }^{94}$

\footnotetext{
${ }_{92}$ El artículo de La DECS señalo que desde el año 2005 al año 2020 existen 1.264.314 registros de apremios personales y que de todos ellos el $49,4 \%$ corresponde a arresto. Véase también: PérEZ, cit. (n. 11), p. 2.

93 Convenio Banco Estado de Chile y Corporación Administrativa del Poder Judicial, "Servicio de consulta en línea de abonos en libretas de ahorro pensión alimenticia", 4 de enero de 2016. Información entregada por Jorge Caballero, administrador del Tercer Juzgado de Familia de Santiago.

${ }^{94}$ Ibíd.
} 


\section{Implementación de las órdenes de arresto}

La ley 14.908 establece un amplio catálogo de medidas de apremio en contra del deudor que incumple la obligación alimentaria, sin embargo, por diversas razones ellas han resultado ser poco efectivas al momento de implementarse en la práctica. ${ }^{95}$

Un ejemplo de ello son las órdenes de arrestos y la forma en que se llevan a cabo por las policías. ${ }^{96}$ Una vez dictada una orden de arresto se despacha un oficio a las policías (Policía de Investigaciones de Chile y Carabineros de Chile) para que esta proceda a su diligenciamiento. En la práctica ello supone la notificación al deudor de la medida decretada y la información de su deber de presentarse ante Gendarmería de Chile en un plazo determinado. Hasta aquí no parece haber problemas, sin embargo, lo que sucede es que las policías cumplen con este mandato solo poniendo en conocimiento del deudor la orden decretada, pero no supervisan la concurrencia de este al recinto penal correspondiente.

Pareciera que se parte de la base de que el deudor apremiado será responsable y concurrirá voluntariamente a las dependencias de Gendarmería de Chile para que se haga efectivo el arresto decretado en su contra, lo que a todas luces parece una ingenuidad mayúscula. El cumplimiento de esta resolución necesita de otra forma de operar de parte de las policías o, al menos, de un control oportuno de los tribunales para que en el caso de incumplimiento se despache de oficio un arresto efectivo -no solo arresto nocturno- como lo faculta el artículo 14 inciso 2 de la ley 14.908, con la subsecuente aprehensión y entrega del deudor a la unidad de Gendarmería que corresponda.

Es posible conjeturar que detrás de esta práctica policial reposa la idea de que las medidas de apremio no siempre tienen debido fundamento o no hay necesidad de llevarlas a cabo con premura, tal vez por ser consideradas desproporcionadas desde la perspectiva de los principios y límites de ius puniendi, en cuya virtud la privación de libertad derivada de resoluciones

\footnotetext{
${ }^{95}$ Pérez, cit. (n. 11), p. 71.

${ }^{96}$ Un análisis sobre la prisión por el no pago de pensiones alimenticias en el derecho comparado, se puede ver en una tesis doctoral de 2019, donde se analiza los antecedentes históricos y principios de esta medida, así como posibles alternativas a ella. ARGOTI, Edwin, "Naturaleza jurídica de la prisión por pensiones alimenticias atrasadas análisis comparado del delito de abandono de familia", Tesis doctoral, Universidad de Salamanca, Salamanca, 2019.
} 
judiciales dictadas por incumplimiento alimenticio carecerían de la entidad o relevancia que tienen las resoluciones que emanan del sistema de justicia penal.

\section{CONCLUSIONES}

En estas páginas hemos analizado algunos de los factores que inciden en la ineficacia del sistema judicial chileno para obtener el cumplimiento de las pensiones de alimentos: ausencia de una perspectiva de derechos humanos; instrumentos legales incompletos y arcaicos; falta de sinergia entre lo jurisdiccional y administrativo, escasa evidencia empírica y, por último, una cultura legal y practicas judiciales que -de una u otra formalimitan la satisfacción de los derechos de los alimentarios/as.

A nuestro juicio, el incumplimiento de las pensiones de alimentos es un problema que va más allá del endurecimiento de las medidas de apremio. Ampliar el catálogo de instrumentos compulsivos, claro que sirve, pero debemos abandonar la creencia que ello por sí solo resolverá el problema sin abordar aspectos procesales, de carácter legal y fáctico, que han ido mermando el potencial reivindicativo de tales medidas.

A problemas complejos, soluciones complejas. Y en este caso, además, soluciones de largo aliento. Aquí presentamos algunas líneas de acción que pueden servir de punto de partida para abrir un debate sobre esta materia. Estas propuestas se han elaborado a la luz de las razones antes desarrolladas, las que a nuestro juicio deben ser evaluadas en forma complementaria con las soluciones a este problema se han dado en otras latitudes. ${ }^{97}$

\footnotetext{
${ }^{97}$ Solo a modo ejemplar una respuesta al problema del incumplimiento de las pensiones de alimentos ha sido por la vía de los subsidios estatales. Esta alternativa es seguida por varios países, entre ellos, España y Francia, que han establecido los llamados fondos de garantía del pago de los alimentos. En el caso español, este fondo opera desde el 2008 y tiene como finalidad garantizar a los alimentarios/as menores de edad el pago de alimentos adeudados que hayan sido decretados y/o aprobados judicialmente. Lo que se busca es adelantar el pago de esas cantidades a los beneficiarios/as, luego de lo cual la entidad a cargo del fondo puede exigir el pago al deudor mediante la subrogación en las acciones (Real Decreto 1617 del 7 de diciembre de 2007 sobre organización y funcionamiento del Fondo de Garantía del Pago de Alimentos). En el caso francés, la ley 75-618 de 1975 establece que si una pensión alimenticia fijada por una decisión judicial, un acuerdo aprobado por un juez/a o vía escritura pública es incumplida podrá ser recuperada a nombre del alimentario por los órganos públicos competentes, siempre que el acreedor acredite haber agotado los medios de ejecución privados que establece la ley. Una vez hecha esta solicitud el acreedor no podrá ejercitar ninguna otra acción para la recuperación de las sumas objeto de esta solicitud y el
} 
En primer lugar, nos parece indispensable abocarse al diseño de un procedimiento de ejecución en materia de familia, en general y de pensiones de alimentos, en particular. Ha de tratarse de un procedimiento adecuado a la naturaleza de las obligaciones cuyo cumplimiento se exige, de factura simple y flexible, pero al mismo respetuoso de los estándares internacionales en materia de ejecución. Por ello, no basta con la sistematización de las normas actualmente dispersas en distintos cuerpos legales, pues ellos han sido dictados en épocas distintas y por tanto obedecen a lógicas diferentes.

En segundo lugar, desde la perspectiva de las prácticas judiciales, se propone al interior del Poder Judicial llevar adelante un trabajo de articulación e integración del enfoque administrativo con el de derechos fundamentales. Ello permitiría compartir una visión global sobre el cumplimiento de las pensiones de alimentos e incorporar nuevas formas de funcionamiento orientadas a la satisfacción de los derechos de los alimentarios/as. Ello se puede realizar a través protocolos de trabajo, los que debieran ser lo suficientemente dúctiles para ajustarse $-y$ reajustarse- cada vez que las prácticas judiciales no logren cumplir el objetivo de recuperar la pensión adeudada.

Esto haría necesario contemplar instancias periódicas de evaluación de sus resultados, procurar la coordinación con otras reparticiones estatales como las policías y el BancoEstado y cuestionar aquellas prácticas que no sean coherentes con una dogmática de derechos fundamentales. Por tanto, no se trata de elaborar más y más protocolos si ellos no retroalimentan el trabajo que a diario desarrollan los tribunales de familia.

En tercer lugar, resulta clave realizar un levantamiento periódico de información sobre el cumplimiento/incumplimiento de las pensiones de alimentos. Pero, para abordar este desafío parece necesario llegar a consensos, al menos, en dos puntos. Primero, definir el criterio para determinar el universo de asuntos a evaluar. Si ello se hará, por ejemplo, por materias, causas o "pares de RUT" 98 u otras categorías. Una vez definido el universo a evaluar es necesario delimitar el subgrupo de causas de alimentos que se encuentran en estado de cumplimiento. Lo anterior

servicio estatal competente se subroga en las acciones y garantías para el cobro de su pensión alimenticia (Ley 75-618 de 1975 relativa a la recuperación pública de las pensiones alimentarias).

${ }^{98}$ Esto último, según la nomenclatura propuesta por la Dirección de Estudios de la Corte Suprema en el estudio de 2020. Dirección de Estudios de la Corte Suprema, cit. (n. 4), p. 28. 
permitiría identificar el tipo de medida de apremio utilizada y si su resultado fue positivo o negativo, es decir, si hubo o no pago de la pensión adeudada. Ello entregaría valiosa información sobre el grado de efectividad de las medidas de apremio existentes. Segundo, es necesario definir el indicador de medición del incumplimiento de las pensiones de alimentos. Este es un tema complejo que requiere hacerse cargo de algunas particularidades del sistema de recolección de datos existente en los tribunales de familia (SITFA). En la actualidad las cifras de incumplimiento solo se pueden obtener cuando los alimentarios/as solicitan la ejecución a través de una medida de apremio.

Sin embargo, es dable suponer que hay una "cifra negra" de alimentarios/as que no reciben el pago de las pensiones y que, pese a ello, no solicitan su ejecución, ya sea por falta de tiempo, por temor, insuficiente conocimiento de sus derechos u otras razones. Recabar dicha información es clave para dimensionar la real magnitud del problema del incumplimiento.

Por otra parte, el sistema computacional SITFA solo permite obtener información sobre si se hizo o no una liquidación de la deuda, es decir, solo se registra el hecho de haberse realizado dicha gestión. Pero no se registra información sobre el contenido de ella, es decir, si hay o no deuda pendiente $y$, si la hubiera, cual es el monto adeudado.

Como se observa, se trata de un sistema de recopilación de información estadística muy rudimentario que refleja una desorientación acerca de los objetivos de las gestiones de la etapa de cumplimiento y que lleva (y ha llevado) consecuentemente a tomar decisiones con información de baja calidad.

Creemos que con un sistema automatizado de liquidación de las deudas sería posible recabar -desde las cartolas de pago- información sobre el cumplimiento requerido, ya que ellas dan cuenta si la pensión de alimentos ha sido o no pagada, en qué fechas y con qué montos. Dicha información, además, debiera quedar registrada en el SITFA para que los jueces/zas de familia puedan hacer uso -si así lo estiman- de la facultad de actuar de oficio que contempla el artículo 14 de la ley 14.908.

Sin embargo, si bien estos dos puntos -universo a evaluar e indicador de medición del incumplimiento-aparecen como "mínimos" de información a levantar, creemos que, en coherencia con la noción de desigualdad estructural antes planteada, también es necesario recoger información sobre el perfil de quienes piden los alimentos (acreedores) y de quienes los deben (deudores). 
Pensamos que siendo las pensiones alimenticias un asunto de familia $\mathrm{y}$ de derechos fundamentales es necesario examinar los patrones culturales y sesgos de género que subyacen a las prácticas judiciales para comprender las dimensiones y complejidades inmersas en el proceso de ejecución en esta materia.

Es necesario hacer este ejercicio tanto desde el punto de vista social, referido al orden de género que informa la cultura vigente ${ }^{99}$ como desde un punto de vista jurídico, en relación con los supuestos de configuración de las normas de ejecución y sus objetivos. Esto último pues dichas normas no han sido promulgadas con un enfoque de derechos sociales ni incluyen en su construcción los intereses y afectaciones de otros sujetos de derecho, como los niños/as y habitualmente sus madres. Por el contrario, las actuales normas han sido diseñadas para garantizar derechos civiles y/o políticos ${ }^{100}$ y en beneficio de un sujeto de derecho que se construye sobre la base de las necesidades de un tipo específico de persona (hombre, adulto, blanco, propietario). ${ }^{101}$

Si el derecho se utiliza sin cuestionamientos como un modelo universal de protección para sujeto de derechos adulto y masculino, la interpretación y aplicación de las normas seguirá replicando un modelo que impide asumir las expectativas de justicia de quienes no forman parte de ese grupo específico y que sigue "los lineamientos de la huella del poder preexistente". ${ }^{102}$ Es así como el derecho termina por configurarse en un fenómeno que excluye "las necesidades de las mujeres tanto de su práctica como de su teoría", 103 fenómeno que por los mismos motivos es posible extender a los niños/as.

Pero junto con el perfil de los litigantes (principalmente adultos), y dado que los principales destinatarios de las pensiones de alimentos son niños/as, resulta necesario recabar información sobre ellos. ¿Qué edad

\footnotetext{
${ }^{99}$ Para ilustrar de mejor modo el concepto, ver: Sсотт, Joan W., "El género: una categoría útil para el análisis histórico", en: LAMAs, Marta (comp.), El género: la construcción cultural de la diferencia sexual, PUEG, México, 1996, pp. 265-302.

${ }^{100}$ Pérez, cit. (n. 11), p. 12. Véase también: Comisión Interamericana de Derechos Humanos, cit. (n. 34), párr. 27 y 235.

${ }^{101}$ Bodelón, Encarna, "Derecho y Justicia no androcéntricos", Quaderns de psicología. International journal of psychology, 2010, Vol. 12, $\mathrm{N}^{\circ}$ 2, p. 190.

${ }^{102}$ FACIO, Alda, "Hacia otra teoría crítica del Derecho", en Fries, L.; FACIO, A. (coords.), Género y Derecho, LOM Ediciones, Santiago, 1999, pp. 15-44.

${ }^{103}$ FACIO, cit. (n. 83), p. 86.
} 
tienen? ¿Están escolarizados? ¿Con quién/es viven? ¿Mantienen una relación directa y regular con el alimentante? ¿Se encuentran en alguna condición de vulnerabilidad, como situación de pobreza o discapacidad? ¿Pertenecen a un pueblo originario?, entre muchas otras.

La comparación de los perfiles de los litigantes más el de los niños/as involucrados podría develar el orden y los prejuicios de género y con ello la necesidad de hacer ajustes en los actuales procedimientos y, a largo plazo, en la forma de intervención estatal en este ámbito.

Por último, tal vez el aspecto más complejo de abordar sea la cultura legal y prácticas judiciales que subyacen al fenómeno del incumplimiento. Sabemos que los cambios de paradigma son transformaciones sustantivas que toman años, sino generaciones; que la resistencia al cambio en los seres humanos es muy poderosa y que movilizar estructuras al interior del Poder Judicial es un desafío de gran envergadura.

Sin embargo, en los últimos años hemos sido testigos de transformaciones radicales acaecidas "en y desde" el Poder Judicial. Una de ellas es la creación en el 2017 de la Secretaría Técnica de Igualdad de Género y No Discriminación a instancias de la Corte Suprema, cuyo objetivo es promover que las y los integrantes del Poder Judicial disfruten de espacios de trabajo igualitarios y libres de violencia y discriminación e impulsar el desarrollo de políticas y acciones dirigidas a garantizar la igualdad y la no discriminación de todas las personas en el acceso a la justicia. ${ }^{104}$

Otra de ellas -y que ha mostrado todo su potencial durante la pandemia del Covid 19- es la Ley de Tramitación Electrónica aprobada en el 2015 y que ha cambiado la forma en que jueces/zas y abogados/as se desempeñan en los estrados, con el uso de la firma electrónica avanzada, la carpeta electrónica y la tramitación digital. ${ }^{105}$

Abrigamos esperanzas de un cambio de paradigma en esta materia. Para ello, es necesario asumir con sinceridad y altura de miras que a la base de este problema se encuentra la desigualdad de los miembros de la familia en la sociedad, en el derecho y en la práctica de los operadores/as jurídicos.

\footnotetext{
${ }^{104}$ Secretaria técnica de Género Poder Judictal (eds.), “¿Quiénes somos?”, página web institucional, 2017, $\mathrm{http} / / /$ secretariadegenero.pjud.cl/index.php/secretaria-tecnica-de-igualdad-de-genero-y-no-discriminacion/ quienes-somos, consultada: 2 de abril de 2021 .

${ }^{105}$ Ley N ${ }^{\circ} 20.886,2015$.
} 


\section{BIBLIOGRAFIA CITADA}

\section{a) Doctrina}

Abeliuk, René. La filiación y sus efectos, Editorial Jurídica de Chile, Santiago, 2001, Tomo I y II.

Argoti, Edwin, "Naturaleza jurídica de la prisión por pensiones alimenticias atrasadas análisis comparado del delito de abandono de familia", Tesis doctoral, Universidad de Salamanca, Salamanca, 2019.

Arancibia, María José; Cornejo, Pablo, "El Derecho de familia en Chile. Evolución y nuevos desafíos", Ius et Praxis, 2014, Vol. 20, N 1.

ARMENTA, Teresa, "Ejecución y medidas conminativas personales. un estudio comparado", Revista de Derecho Universidad Católica del Norte, 2015, Vol. 22, $\mathrm{N}^{\circ} 2$, pp. 23-54.

Bodelón, Encarna, "Derecho y Justicia no androcéntricos", Quaderns de psicologia, International journal of psychology, 2010, Vol. 12, $\mathrm{N}^{\circ} 2$.

Bordalí, Andrés, "Análisis crítico de la jurisprudencia del Tribunal Constitucional sobre el derecho a la tutela judicial efectiva", Revista Chilena de Derecho, 2011, Vol. 38, ${ }^{\circ} 2$.

Casarino, Mario, Manual de Derecho Procesal, Editorial Jurídica de Chile, Santiago, 2005-2007, T. V.

Correa, Jorge, Juicio Ejecutivo. Doctrina y jurisprudencia, Lexis Nexis, Santiago, 2003.

Facio, Alda, "Hacia otra teoría crítica del Derecho", en Fries, L.; Facio, A. (coords.), Género y Derecho, LOM Ediciones, Santiago, 1999, pp. 15-44.

FACiO, Alda, "Con los lentes del género se ve otra justicia", El otro derecho (Bogotá), 2002, N² 28, pp. 85-102.

Fuentes, Claudio, "Los dilemas del juez de familia", Revista Chilena de Derecho, 2015, Vol. 42, no 3, pp. 957-961.

Fuentes, Claudio; GarCía, Ramón; Silva, Rodrigo, Gestión y control judicial de la litigación: case management, DER Ediciones, Santiago, 2021.

García, Gonzalo; Contreras, Pablo, "El derecho a la tutela judicial y al debido proceso en la jurisprudencia del Tribunal Constitucional chileno", Revista de Estudios Constitucionales, 2013, Vol. 11, N 2, pp. 229-282.

GARRIDO, Carlos, Derecho de alimentos, análisis actualizado y formularios, Editorial Metropolitana, Santiago, 2020.

Gomez DE LA Torre, Maricruz, El sistema filiativo chileno, Editorial Jurídica de Chile, Santiago, 2007.

GreEven, Nel, Derecho de alimentos como derecho humano y apremios para obtener el cumplimiento, Librotecnia, Santiago, 2018.

Greeven, Nel; Orrego, Juan Andrés, Alimentos y su ejecución en materia de familia, DER Ediciones, Santiago, 2018. 
Hoyos, Francisco, Temas fundamentales de Derecho Procesal, Editorial Jurídica de Chile, Santiago, 1987.

KIMMEL, Michael, Hombres (blancos) cabreados la masculinidad al final de una era, Editorial Barlin Libros, Valencia, 2014.

KoDEK, George E., "The impact of the European convention on human Rights and the fundamental liberties on enforcement practices", en: ANDENAS, M., Hess, B., Oberhammer, P. (eds.) Enforcement agency practice in Europe, BIICL, London, 2005.

LiLlo, Lenin, Manual de Juicio Ejecutivo, Ediciones Jurídicas de Santiago, 2003.

LiLlo, Ricardo, "La justicia civil en crisis. Estudio empírico en la ciudad de Santiago para aportar a una reforma judicial orientada hacia el acceso a la justicia (formal)", Revista Chilena de Derecho, 2020, Vol. 47, № 1.

Nevado, Juan José, “La oposición a la ejecución de pensiones alimenticias. referencia a la posibilidad de extinción de la pensión alimenticia en el procedimiento ejecutivo", Actualidad Jurídica Iberoamericana, 2019, № extra, 10, N², pp. 736745.

Orellana, Fernando, Manual de Derecho Procesal, Librotecnia, Santiago, 2008, T. III.

Orellana, Fernando, “Algunos aspectos del inicio del proceso de ejecución en el proyecto de Código Procesal Civil, en Justicia Civil: perspectivas para una reforma en la legislación chilena", Cuadernos de Extensión Jurídica, Eds. Universidad de los Andes, Santiago, 2012.

PaJic, Natasa, "Avenues for enforcement and execution of judgments in the United States", en: VAN Rhee, C.H.; Uzelac, A. (eds.), Enforcement and Enforceability. Tradition and reform, Intersentia, Antwerp-Oxford-Portland, 2010, pp. 237-250.

PAlOMo, Diego, "Reformas de la ejecución civil y del proceso monitorio: la apuesta chilena por la tutela judicial efectiva y el derecho de acceso a un debido proceso", Estudios Constitucionales, 2014, No 12.

PÉrez, Paz, Incumplimiento de alimentos en la justicia de familia, DER Ediciones, Santiago, 2021.

PÉrez, Álvaro, "Derecho a la tutela ejecutiva del crédito: entre mitos, temores y realidad", en: Aguirrezabal, M. (ed.), Cuadernos de Extensión Jurídica, $\mathrm{N}^{\circ} 23$, Eds. Universidad de los Andes, Santiago, 2013.

PÉrez, Álvaro, Ejecución civil. Cómo lograr el cumplimiento del deudor, Editorial Astrea, Buenos Aires, 2019.

PÉrez, Álvaro; NúÑEz, Raúl; VARGAS, Macarena, Hacia una mejor ejecución civil, Thomson Reuters, Santiago, 2013.

Ramos, René, Derecho de Familia, Editorial Jurídica de Chile, Santiago, 2009, T. I y II. 
Schмid, Claudia, Del derecho alimentario familiar en la filiación, Editorial Punto Lex, Santiago, 2008.

Silva, J.P., García, J.F., LetURia, F.J. (eds.), Justicia civil y comercial. Una reforma pendiente: bases para el diseño de la reforma procesal civil, Instituto Libertad y Desarrollo, Universidad Autónoma de Madrid, Santiago, 2006.

SiLVA, Oscar, La transparencia patrimonial del deudor en la ejecución civil, Thomson Reuters, Santiago, 2014.

Sсотт, Joan W., "El género: una categoría útil para el análisis histórico", en: LAMAs, Marta (comp.), El género: la construcción cultural de la diferencia sexual, PUEG, México, 1996, pp. 265-302.

Trocker, Nicolo, "The Right to an Effective Enforcement of Civil Judgments and Orders: Lessons from the Case Law of the European Court of Human Rights", en: Stürner, R.; Kawano, M. (eds.), Comparative Studies on Enforcement and Provisional Measures, Mohr-Siebeck, Tübingen, 2011.

Troncoso, Hernán, Derecho de Familia, Thomson Reuters, Santiago, 2020.

VARGAS, Macarena, "Reflexiones en torno a la figura del oficial de ejecución", en Leturia, F.J. (ed.), Justicia Civil y Comercial: Una Reforma ¿Cercana?, Ediciones LYD, Santiago, 2011.

VARGAS, Macarena, "¿De qué hablamos cuando hablamos de acceso a la justicia? Un intento por iluminar el debate", en Machado, P.; Larroucau, J. (coords.), Estudios de Derecho Procesal, DER Ediciones, Santiago, 2019, pp. 233252.

VARGas, Macarena, El derecho a la ejecución forzada. Noción e implicancias a la luz de la jurisprudencia de la Corte Europea de Derechos Humanos, Ediciones Universitarias de Valparaíso, Valparaíso, 2019.

Vodanovic, Antonio, Derecho de alimentos, Editorial Jurídica Conosur, Santiago, 1994.

b) Legislación

Ley $\mathrm{N}^{\mathrm{o}}$ 1.552, Código de Procedimiento Civil, 1902.

Ley $\mathrm{N}^{\mathrm{o}} 14.908$, Fija el texto definitivo y refundido de la Ley número 5.750, con las modificaciones introducidas por la ley número 14.550, 1962.

Ley N ${ }^{\circ}$ 19.968, Crea los Tribunales de Familia, 2004.

Ley No 20.886, Modifica el Código de Procedimiento Civil, para establecer la tramitación digital de los procedimientos judiciales, 2015.

Boletín 8197-07, Proyecto de ley que crea el Nuevo Código Procesal Civil, 12 de marzo de 2012.

Boletín 7.765-07, Proyecto de Ley respecto de comunicaciones de órdenes de apremio en juicios de alimentos, 6 de julio de 2011.

Boletín 13.465-18, Proyecto de ley que modifica la Ley $\mathrm{N}^{\circ} 14.908$, sobre Abandono de familia y pago de pensiones alimenticias, en materia de retención de 
parte del sueldo del alimentante, para garantizar el pago de la pensión, 28 de abril de 2020.

Boletín 12.182-18, Proyecto de ley que modifica la ley $\mathrm{N}^{\circ} 14.908$, sobre Abandono de Familia y Pago de Pensiones Alimenticias, en materia de apremios, 18 de octubre de 2018.

Boletín $\mathrm{N}^{\circ} 10.259-18$, Proyecto de ley que propone crear el Registro Nacional de Deudores de Pensiones Alimenticias, 13 de agosto de 2015.

Boletín $\mathrm{N}^{\circ} 10.450-18$, Proyecto de ley que propone modificar el Código Civil y la Ley 14.908 en materia de cobro y ejecución de deudas por pensión alimenticia, 16 de diciembre de 2015.

Boletín $\mathrm{N}^{\circ} 11.738-18$, Proyecto de ley que propone modificar la Ley 14.908 en cuanto a exigir la incorporación de los deudores de pensiones insolutas a una nómina nacional y pública, 15 de mayo de 2018 .

Boletín $\mathrm{N}^{\circ} 11.813-18$, Proyecto de ley que busca aumentar las sanciones al alimentante que incumple su obligación de pago, 13 de junio de 2018.

Boletín N ${ }^{\circ} 12.244-18$, Proyecto de ley que busca modificar la Ley $\mathrm{N}^{\circ} 14.908$ para así hacer aplicables las medidas de apremio para el cobro de pensiones impagas, cualquiera sea la edad del alimentante, 15 de noviembre de 2018.

Boletín $\mathrm{N}^{\circ} 12.394-18$, Proyecto de ley que propone modificar la Ley $\mathrm{N}^{\circ}$ 29.066 (ley de violencia intrafamiliar) para así sancionar como maltrato habitual el incumplimiento reiterado en el pago de pensiones, 17 de enero de 2019.

Boletín 12.068-18, que incorpora como crédito de primera clase a los alimentos que se adeuden a los descendientes, 6 de septiembre de 2018.

Boletín 12.147-18, que modifica el Código Civil y el Decreto Ley $\mathrm{N}^{\circ} 3.500$, de 1980, que establece nuevo sistema de pensiones, para otorgar privilegio al crédito que deriva de los alimentos que se deben por ley, de modo que se paguen con preferencia a las cotizaciones previsionales y otras prestaciones, 11 de septiembre de 2018.

Boletín 13.330-07, Proyecto de ley que incorpora a los deudores de pensiones de alimentos al Boletín de Informaciones Comerciales, 23 de marzo de 2020.

Boletín 14.077-18, Proyecto de ley que modifica la Ley $\mathrm{N}^{\circ} 14.908$, sobre Abandono de familia y pago de pensiones alimenticias, y crea el Registro Nacional de Deudores de Pensiones de Alimentos, 8 de marzo de 2021.

\section{c) Jurisprudencia}

Corte Europea de Derechos Humanos, sentencia de 13 de julio de 1983, Caso Zimmermann and Steiner v. Suiza.

Corte Europea de Derechos Humanos, sentencia de 23 de marzo de 1994, Caso Silva Pontes v. Portugal.

Corte Europea de Derechos Humanos, sentencia de 26 de septiembre de 1996, Caso Di Pede v. Italia.

Corte Europea de Derechos Humanos, sentencia de 19 de marzo de 1997, 
Caso Hornsby v. Grecia.

Corte Europea de Derechos Humanos, sentencia de 27 de junio de 2000, Caso Nuutinen v. Finlandia.

Corte Europea de Derechos Humanos, sentencia de 31 de marzo de 2005, Caso Matheus v. Francia.

Corte Europea de Derechos Humanos, sentencia de 7 de junio de 2005, Caso Fuklev v. Ucrania.

Corte Europea de Derechos Humanos, sentencia de 8 de diciembre de 2005, Caso Dumanovski v. República de Macedonia.

Corte Europea de Derechos Humanos, sentencia 28 de noviembre de 2006, Caso Apostol v. Georgia.

Corte Europea de Derechos Humanos, sentencia de 21 de junio de 2012, Caso Olsby v. Suecia.

Corte Interamericana de Derechos Humanos, Caso Mejía Idovro vs. Ecuador, sentencia de 5 de julio de 2011.

Corte Interamericana de Derechos Humanos, Caso Cinco pensionistas vs. Perú, sentencia de 28 de febrero de 2003.

Corte Interamericana de Derechos Humanos, Caso Furlan vs. Argentina, sentencia de 31 de agosto de 2012.

Corte de Apelaciones de Santiago, Rol Amparo 5361-2021, sentencia de 18 de noviembre de 2021.

Corte de Apelaciones de Santiago, Rol Amparo 2922, sentencia de 17 de diciembre de 2020.

Corte de Apelaciones de Santiago, Rol Amparo 2694, sentencia de 24 de noviembre de 2020.

Corte de Apelaciones de Santiago, Rol Amparo 1489, sentencia de 1 de julio de 2020 .

\section{d) Informes}

Casen, "Caracterización de la Mujer en Chile", 2017, https://minmujeryeg. gob.cl/wp-content/uploads/2020/03/Casen-2017-Mujer-Estudios.pdf.

Centro UC de la FAmilia, "Informe Final sobre estudio, análisis y propuestas en materia de procedimiento y cumplimiento en el pago de las pensiones alimenticias", Santiago, 2011.

Centro UC Políticas Públicas, "Propuestas para Chile. Capítulo X: Pago de pensiones alimenticias: avanzando hacia una real y eficiente tutela de la infancia y la familia", 2014, https://politicaspublicas.uc.cl/wp-content//uploads/2015/06/ Propuestas-para-Chile-2014_Cap\%C3\%ADtulo-10_Valdivia.pdf.

Comisión Interamericana de Derechos Humanos, "El acceso a la justicia como garantía de los derechos económicos, sociales y culturales. Estudio de los estándares fijados por el sistema interamericano de derechos humanos", 2007, http://www.cidh.org/pdf\%20files/ACCESO \%20A\%20LA\%20JUSTICIA \%20 


\section{DESC.pdf.}

Dirección de Estudios de la Corte Suprema, "Problemáticas de la etapa de cumplimiento en materia de alimentos. Una visión práctica", 2020, http:// decs.pjud.cl/articulo-problematicas-de-la-etapa-de-cumplimiento-en-materia-dealimentos-una-vision-practica/.

Ministerio de Desarrollo Social y Familia, "Informe Desarrollo Social 2019”, http://www.desarrollosocialyfamilia.gob.cl/storage/docs/Informe_de_ Desarrollo_Social_2019.pdf.

Ministerio DE Justicia, "Informe final Panel de Expertos para la creación de un modelo orgánico de oficial de ejecución”, 2013, http://rpc.minjusticia.gob.cl/ media/2013/07/Informe-Final-Modelo-Organico.pdf

\section{e) Noticias y Prensa}

Noticia: "El 84\% de las pensiones se encuentran impagas: ¿por qué los chilenos no pagan la pensión alimenticia a sus hijos?", La Tercera, 2020, https:// www.latercera.com/que-pasa/noticia/el-84-de-las-pensiones-se-encuentranimpagas-por-que-los-chilenos-no-pagan-la-pension-alimenticia-a-sus-hijos/ R35K3FMPGNDZ5DR4VWGWGAF5SU/, consultada: 27 de abril de 2021.

Noticia: "Ministro de Desarrollo Social: "E184\% de las pensiones alimenticias no se pagan", ADN Radio, 2020, https:/www.adnradio.cl/nacional/2020/03/10/ ministro-de-desarrollo-social-el-84-de-las-pensiones-alimenticias-no-se-pagan. html, consultada: 27 de abril de 2021.

Noticia: "Abogada de familia: Un $84 \%$ de los papás no paga la pensión de alimentos", Radio Concierto, 2020, https://www.concierto.cl/2020/03/abogadade-familia-un-84-de-los-papas-no-paga-la-pension-de-alimentos/, consultada: 27 de abril de 2021.

Noticia: "El pago de la pensión de alimentos en Chile, Diario Concepción, https://www.diarioconcepcion.cl/editorial/2020/08/12/el-pago-de-la-pension-dealimentos-en-chile.html, consultada: 27 de abril de 2021.

Cortez-Monroy, Fabiola, Opinión: "Pago de pensiones de alimentos: ¿de quién es la deuda?", 2020, https://www.ciperchile.cl/2020/08/06/pago-depensiones-de-alimentos-de-quien-es-la-deuda/.

\section{f) Otros}

Convenio Banco Estado de Chile y Corporación Administrativa del Poder Judicial. Servicio de consulta en línea de abonos en libretas de ahorro pensión alimenticia. 4 de enero de 2016.

Secretaria técnica de GÉnero Poder Judicial (eds.), “Quiénes somos?”, página web institucional, documento .html, 2017, http://secretariadegenero.pjud. $\mathrm{cl} /$ index.php/secretaria-tecnica-de-igualdad-de-genero-y-no-discriminacion/ quienes-somos. 